\title{
Expression and Immunogenicity of the Mycobacterial Ag85B/ESAT-6 Antigens Produced in Transgenic Plants by Elastin-Like Peptide Fusion Strategy
}

\author{
Doreen Manuela Floss, ${ }^{1,2}$ Michael Mockey, ${ }^{3}$ Galliano Zanello, ${ }^{4}$ Damien Brosson, ${ }^{5}$ \\ Marie Diogon, ${ }^{5}$ Roger Frutos, ${ }^{6}$ Timothée Bruel, ${ }^{4}$ Valérie Rodrigues, ${ }^{3}$ Edwin Garzon, ${ }^{3}$ \\ Claire Chevaleyre, ${ }^{4}$ Mustapha Berri, ${ }^{4}$ Henri Salmon, ${ }^{4}$ Udo Conrad, ${ }^{1}$ and Laurence Dedieu ${ }^{3}$ \\ ${ }^{1}$ Leibniz Institute of Plant Genetics and Crop Plant Research (IPK), Corrensstrasse 3, 06466 Gatersleben, Germany \\ ${ }^{2}$ Institute of Biochemistry, Christian Albrechts University, Olshausenstrasse 40, 24118 Kiel, Germany \\ ${ }^{3}$ CIRAD, UMR CMAEE, 34398 Montpellier, France \\ ${ }^{4}$ Institut National de la Recherche Agronomique (INRA), UR1282, Infectiologie Animale et Santé Publique, 37380, \\ Nouzilly (Tours), France \\ ${ }^{5}$ Laboratoire "Microorganismes: Génome et Environnement" (LMGE), Equipe Interactions Hôtes-Parasites, 24, avenue des landais, \\ 63177 Aubière Cedex, France \\ ${ }^{6}$ CIRAD, UMR 17, 34398 Montpellier, France
}

Correspondence should be addressed to Laurence Dedieu, laurence.dedieu@cirad.fr

Received 3 September 2009; Accepted 15 January 2010

Academic Editor: Don Mark Estes

Copyright (c) 2010 Doreen Manuela Floss et al. This is an open access article distributed under the Creative Commons Attribution License, which permits unrestricted use, distribution, and reproduction in any medium, provided the original work is properly cited.

This study explored a novel system combining plant-based production and the elastin-like peptide (ELP) fusion strategy to produce vaccinal antigens against tuberculosis. Transgenic tobacco plants expressing the mycobacterial antigens Ag85B and ESAT-6 fused to ELP (TBAg-ELP) were generated. Purified TBAg-ELP was obtained by the highly efficient, cost-effective, inverse transition cycling (ICT) method and tested in mice. Furthermore, safety and immunogenicity of the crude tobacco leaf extracts were assessed in piglets. Antibodies recognizing mycobacterial antigens were produced in mice and piglets. A T-cell immune response able to recognize the native mycobacterial antigens was detected in mice. These findings showed that the native Ag85B and ESAT6 mycobacterial B- and T-cell epitopes were conserved in the plant-expressed TBAg-ELP. This study presents the first results of an efficient plant-expression system, relying on the elastin-like peptide fusion strategy, to produce a safe and immunogenic mycobacterial Ag85B-ESAT-6 fusion protein as a potential vaccine candidate against tuberculosis.

\section{Introduction}

Tuberculosis (TB) remains one of the major infectious diseases, which continues to pose a major global health problem. Mycobacterium tuberculosis is the main TB-causing micro-organism in human. However, the zoonotic disease bovine TB, caused by the closely related $M$. bovis, poses a significant threat to human health and can be responsible for up to $10 \%$ of human TB cases [1-4]. Therefore, both human and bovine TB should be targeted for an efficient control strategy. Here, vaccination remains the most promising approach and also the most common. Bovine TB might also be an efficient model for human TB, allowing the testing of innovative vaccines $[5,6]$.

The only available vaccine against TB is still the $M$. bovis Bacillus Calmette-Guerin (BCG). It has been distributed since the 1920s and more than three billion people have received this vaccine. BCG vaccination, however, remains a matter of debate due to safety aspects, loss of sensitivity to tuberculin as a diagnostic reagent, and varying efficacy (from 0 to $85 \%$ ) in different BCG vaccine trials $[7,8]$. Better TB vaccines are urgently needed. Subunit vaccines are 
a promising strategy since, in contrast to BCG, they are not compromised by exposure to environmental mycobacteria $[8,9]$. They can also be retained as a booster to BCG priming, thus prolonging immunity to also cover the adult population [9].

Several TB subunit vaccines have been developed, mainly based on $M$. tuberculosis-secreted components such as the early secretory antigenic target, ESAT-6, and the antigen 85B (Ag85B). Both antigens have an impressive track record of studies, also in humans, confirming their antigenicity and vaccine potential [9-11]. ESAT-6 and Ag85B, both common to $M$. tuberculosis and $M$. bovis, might lead to effective vaccines against human and bovine TB.

However, even though efficient vaccinal antigens have been identified, the cost constraints related to vaccine production, distribution, and delivery remain prohibitive to widespread administration in developing countries where vaccines are needed the most.

Plants might be attractive vehicles to overcome these constraints. Since the first report about a plant-derived vaccine $[12,13]$, a large number of species (i.e., tobacco, corn, rice, lettuce, and alfalfa) have been used for vaccine production and evaluated in different hosts [14-16]. Plants are easy and inexpensive to grow and are versatile systems with minimum manufacture and processing requirements, amenable to rapid and economical scale-up. They have reduced risks of contamination with human or animal pathogens. Regarding food plants, edible vaccines eliminate the need for needles and skilled personnel for administration and for refrigerated storage, which is particularly attractive for developing countries [15, 17]. Vaccination by oral delivery of plant-based vaccines to humans, or by feeding large animals, has been proven efficient [1820].

Various strategies have been described to express foreign proteins in plants $[16,17]$. Among them, fusion to elastinlike peptides (ELP) has been proved promising. It has been shown, in particular, to enhance the expression of spider silk proteins $[21,22]$, human interleukin-10 and murine interleukin-4 [21], single-chain variable fragment $(\mathrm{scFv})$ antibodies [23], and full-length antibodies [24, 25]. Synthetic ELPs are designed around the characteristic VPGVP motif found in native mammalian elastins [26], utilizing repeats of the pentapeptide VPGXG, where X can be any amino acid except proline [27]. A major advantage is the simple and inexpensive purification procedure, called inverse transition cycling (ITC), initially used for the purification of E. Coliexpressed recombinant proteins [27]. This method has been further improved for ELP-containing pharmaceutical proteins expressed in plants [24, 27-29]. The use of ELPs, as delivery vectors for chemotherapeutic drugs and therapeutic peptides [30] or elastin-like polymers with emphasis on medical uses [31], is well described and a main focus of future research in human therapeutics [32]. In addition, ELPs are biocompatible [33], making them suitable for in vivo applications [34]. The ELP plant-based expression strategy might thus be a valuable approach to develop vaccines targeting diseases with enormous impact on developing countries, such as TB.
For optimum plant expression, three main aspects have to be considered: the $\mathrm{G}+\mathrm{C}$ content, codon usage, and presence of destabilizing AT-rich sequences. M. tuberculosis and $M$. bovis are characterized by a high $\mathrm{G}+\mathrm{C} \%(64 \%$ to $66 \%$ ) whereas Nicotiana tabacum has a lower G+C\% (43.72\%) [35]. This results in a clear difference of codon usage and may generate unwanted recognition of ATrich-destabilizing sequences or other regulatory sequences, known to be detrimental for expression. Such problems were successfully overcome to develop insect-resistant BT crytransgenic crops by designing synthetic genes encoding the same protein but with adapted plant codon usage and $\mathrm{G}+\mathrm{C}$ contents $[36,37]$.

In this study, we tested the efficacy of the ELP fusion strategy for expressing the Ag85B/ESAT-6 fusion protein (TBAg) in transgenic tobacco plants. The plant-made TBAgELP immunogenicity was assessed in mice, as a reference laboratory model and piglets, as a preclinical model of human vaccination. Swine, moreover, as natural hosts for Mycobacterium species, might be representative of a human TB model $[38,39]$. In addition, as a first step towards cattle application, in vitro experiments were also performed with bovine immune cells. The aim of this study was to determine the feasibility of using tobacco plant-based vaccines against bovine and human TB based on the ELP strategy.

\section{Materials and Methods}

2.1. Production of Plant-Expressed TBAg-ELP Fusion Protein. An Ag85B/ESAT-6 (TBAg) gene cassette was first synthesized by the recursive asymmetric PCR method (Figure 1) [40]. Briefly, the sequences, Ag85B (P31952) and ESAT-6 (AAL16896), were modified "in silico," to optimize codon usage for plants, eliminate the 6-base restriction sites, and remove $\mathrm{A}+\mathrm{T}$-rich destabilizing sequences, while maintaining the amino acid (aa) sequences (Windows Biological Sequence Alignment tool, BioEdit). Sequences were then divided into 3 blocks $(267,308$, and $314 \mathrm{nt}$ ) for Ag85B and one $(314 \mathrm{nt})$ for ESAT-6. Each block was created in vitro by asymmetric PCR using a total of five 65 to 70 mer oligonucleotides, cloned into pGEM(T)-easy (Promega, Charbonnières-les-Bains, France) and sequenced to ensure the absence of mismatches. Blocks were flanked by "suicidal" restriction sites to allow further assembly of the fulllength cassette. NsiI and ApaI restriction sites were created upstream and downstream, respectively, to allow cloning into pGEM(T)-easy and removal of the whole TBAg cassette.

The synthetic TBAg cassette was then inserted into a plant expression system. The TBAg cassette was first amplified by PCR using two specific primers, each containing a BamHI site and, for the reverse primer, without the stop codon. The cassette was cloned as a BamHI fragment in the plasmid pRTRA-100xELP containing the ubiquitous Cauliflower Mosaic Virus (CaMV) $35 \mathrm{~S}$ promoter $[41,42]$, the legumin B4 (LeB4) signal peptide [43], the c-myc tag (EQKLISEEDLN; [44]), the sequence encoding the 100xELP fusion protein, and the KDEL endoplasmic reticulum (ER) retention signal to produce the construct 


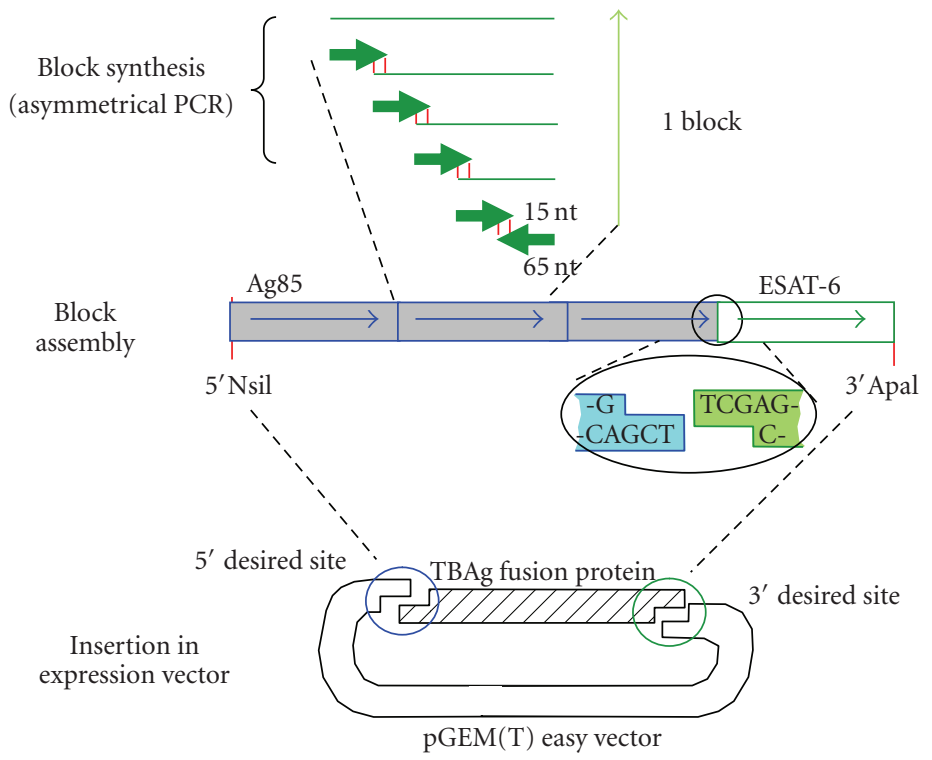

FIGURE 1: Diagrammatic representation of the Ag85B/ESAT-6 fusion cassette. The strategy used was recursive asymmetric PCR. In silico modified Ag85B and ESAT-6 gene sequences were divided into 3 blocks (267, 308, and $314 \mathrm{nt)} \mathrm{for} \mathrm{Ag85B} \mathrm{and} \mathrm{one} \mathrm{(314} \mathrm{nt)} \mathrm{for} \mathrm{ESAT-6.} \mathrm{Each}$ block was created by asymmetric PCR using five 65 to 70-mer primers then cloned into pGEM(T)-easy. Blocks were flanked by "suicidal" restriction sites to allow further assembly of the full-length cassette. NsiI and ApaI restriction sites were created upstream and downstream, respectively, to allow cloning into the $\operatorname{pGEM}(\mathrm{T})$-easy and removal of the whole TBAg cassette.

pRTRA-TBAg-ELP. The 100xELP fusion protein, previously described by Scheller and coworkers [22], contained 100 repeats of the pentapeptide VPGXG with X being glycine, valine, or alanine. The expression cassette (Figure 2(a)) was excised by HindIII and inserted into the binary vector pCB301-Kan [45], which is based on the binary vector pCB301 [46]. The resulting binary vector was introduced into Agrobacterium tumefaciens C58C1 (pGV2260; [47]) and functionally tested in transient expression assays by agroinfiltration $[48,49]$. Stable transgenic tobacco plants (Nicotiana tabacum cv. Samsun NN) were generated using the leaf disk transformation method [50] and grown on MurashigeSkoog medium [51] containing $50 \mathrm{mg} / \mathrm{L}$ kanamycin prior to transfer to soil in the greenhouse. In parallel, a construct lacking the 100xELP sequence was prepared and used for Agrobacterium-mediated transformation of tobacco (D. Floss and U. Conrad unpublished).

\subsection{Purification and Characterization of TBAg-ELP Fusion Protein from Tobacco Leaves}

2.2.1. Preparation of Tobacco Leaf Extracts. Leaves from TBAg-ELP transgenic tobacco plants and plants accumulating the 100xELP protein were prepared for in vivo immunogenicity assay and leaves from nongenetically modified plants (wild-type, WT) were used for cytotoxicity evaluation.

The tobacco leaf extracts (TLEs) were prepared by crushing frozen leaves $\left(-80^{\circ} \mathrm{C}\right.$ or liquid nitrogen $)$ and homogenizing in $100 \mathrm{mM}$ Tris. These TLEs were used for the piglet cytotoxicity assay to assess the crudest preparation of tobacco plant-based vaccine. Otherwise, TLEs were cleared by filtration and centrifugation ( 20 minutes, $15,000 \mathrm{~g}, 4^{\circ} \mathrm{C}$ ). For in vitro assays, an extraction buffer $(50 \mathrm{mM}$ Tris- $\mathrm{HCl}$ pH8; $1 \mathrm{mM}$ EDTA; 0.1\% Triton X100; $1 \mathrm{mM}$ DTT; 5\% glycerol) was used (Breitler, personal communication), then TLEs were centrifuged and dialyzed overnight (Slide A Lyzer, Perbio, France). The concentration of total soluble proteins (TSPs) was determined by Bradford assay (Bio-Rad, Munich, Germany) or NanoDrop (Thermo Fisher Scientific, Cergy, France).

2.2.2. SDS-PAGE and Immunoblotting Analyses. Electrophoresis and Western blot were performed using TBAg-ELP transgenic tobacco as previously described [22]. TBAg-ELP protein was detected by the ECL Western blotting analysis system using anti-c-myc (9E10) supernatant followed by horseradish peroxidase- (HRP-) conjugated sheep antimouse IgG (Amersham Biosciences, Piscataway, NJ, USA). The TBAg-ELP in leaf extracts was quantified by comparison between dilutions of the TLE-TBAg-ELP, from $2 \mu \mathrm{g}$ to $0.25 \mu \mathrm{g}$ of TSP, and the recombinant c-myc-tagged IL- 6 as standard.

2.2.3. Purification of the ELP Fusion Proteins by "Inverse Transition Cycling" (ITC). The recombinant proteins TBAgELP and 100xELP were purified from tobacco leaves by inverse transition cycling (ITC), based on the salt- and temperature-dependent phase transition of the elastin-like polypeptides [27] as described [22, 24]. 


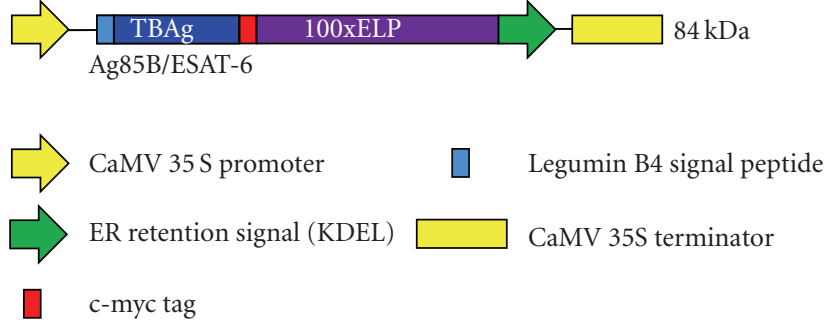

(a)

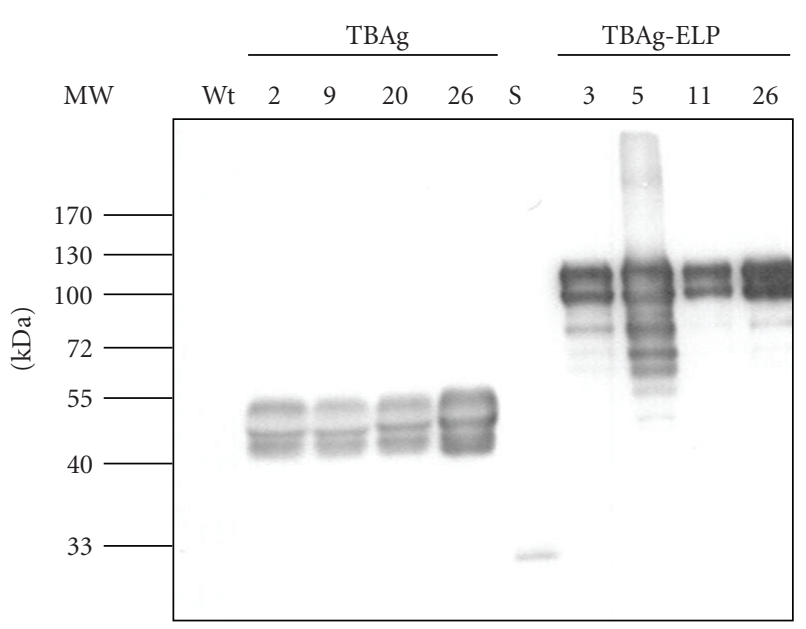

(b)

FIgure 2: Production of plant-expressed TBAg-ELP fusion protein. (a) Diagrammatic representation of the TBAg-ELP expression cassette. Expression of the recombinant fusion protein was driven by the constitutive CaMV 35S promoter. Endoplasmic reticulum retrieval was mediated by a C-terminal KDEL tag and the c-myc tag was included to facilitate detection. ELP fusion consisted of 100 repeats of the pentapeptide VPGXG, where X was valine, glycine, or alanine (100xELP). (b) Accumulation increase of TBAg-ELP in transgenic tobacco plants. Western blot analysis of leaf extracts of individual $T_{0}$ plants expressing the transgene. Proteins were separated by reducing $10 \%$ SDSPAGE, blotted, and immunodetected using an anti-c-myc antibody. Numbers designate the independent $T_{0}$ plants. The same amounts of TSP were loaded on the gel (15 $\mathrm{g}$ /lane). S: cmyc standard (15 ng/lane); Wt: wild-type N. tabacum.

\subsection{Animals, Cell Preparation, and Analysis}

\subsubsection{Animals and Cell Preparation}

(1) Mouse. BALB/c mice aged 6-8 weeks were used for in vitro experiments and C57BL/6 mice aged 12 weeks for in vivo immunization (Charles Rivers, Lyon, France). Experiments were conducted in accordance with national guidelines for animal care. BALB/c mice spleen cells were obtained by spleen dissociation, nylon membrane passage, and red blood cell elimination. Spleen cells were washed, counted, and resuspended in complete RPMI (cRPMI) containing RPMI-1640-medium with 10\% foetal calf serum (FCS), $2 \mathrm{mM}$ L-glutamine and $5 \cdot 10^{-5} \mathrm{M} \mathrm{2-}$ mercaptoethanol (Eurobio, Les Ulis, France), $100 \mathrm{U} / \mathrm{mL}$ penicillin G, and $100 \mu \mathrm{g} / \mathrm{mL}$ streptomycin (Sigma, St. Quentin, France). Mouse bone marrow-derived dendritic cells (mBM-DC) were generated as described in [52] by depletion of lymphocytes, macrophages, and granulocytes and 6 days' culture in cRPMI containing the mouse recombinant granulocyte/macrophage colony-stimulating factor (rmGM-CSF, $6 \mathrm{ng} / \mathrm{mL}$ ) and interleukin-4 (rmIL-4, $3 \mathrm{ng} / \mathrm{mL}$ ) (R\&D Systems, Lille, France).

(2) Cattle. Blood was taken into heparin-containing vacutainer tubes (BD-Pharmingen, Le Pont de Claix, France) from two naive cattle hosted at the CIRAD animal facility. Peripheral blood mononuclear cells (PBMCs) were collected by density gradient centrifugation as previously described [53]. Bovine monocyte-derived dendritic cells (Bo-Mo-DC) were prepared from CD14-expressing cells using $40 \mathrm{ng} / \mathrm{mL}$ of both bovine recombinant IL- 4 and GM-CSF as described in [54].
(3) Piglets. Large white neonate piglets aged 10-31 days were used to evaluate TLE toxicity and aged 33-61 days to assess the immunogenicity of the plant-made TBAg-ELP. Piglets were housed in the INRA experimental unit and received a standard diet twice a day. During the experiment, animals were cared for in accordance with the guidelines of the INRA Institutional Animal Care and Use Committee.

2.3.2. Flow Cytometry Analysis. The mouse BM-derived DC surface markers CD40, CD80, and CD86 and major histocompatibility complex class II molecules (MHC II) were stained using monoclonal antibodies (mAbs) conjugated to fluorescein isothiocyanate (FITC) or phycoerythrin (PE) (BD-Pharmingen, Le Pont de Claix, France). Bovine cell surface markers were stained (10 minutes, RT) with mouse antibovine mAbs to MHC II (ILRI, Nairobi, Kenya), CD40, CD80, and CD86 (provided by J Hope, IAH, Compton, UK). Cells were washed with $\mathrm{PBS}$ (without $\mathrm{Ca}, \mathrm{Mg}$ ) containing $1 \%$ BSA $0.1 \%$ sodium azide and revealed by FITC-antimouse IgG (Tebu, Le Perray, France).

To determine cell proliferation, $2 \times 10^{7}$ cells were suspended in Hanks-balanced salt solution $(1 \mathrm{~mL})$ and stained with carboxyfluorescein diacetate succinimidyl ester (CFSE, $1 \mu \mathrm{M}$ final, Invitrogen, Cergy-Pontoise, France). After 10 minutes at $37^{\circ} \mathrm{C}$, the reaction was stopped by an equal volume of cold heat-inactivated FCS. Afterwards, cells were washed in RPMI containing 10\% FCS and processed for stimulation assays.

To determine cytotoxicity, $2 \mu \mathrm{L}$ of propidium iodide ( $50 \mu \mathrm{g} / \mathrm{mL}, \mathrm{BD}$-Pharmingen, France) were added after the last wash to each tube, kept at $4^{\circ} \mathrm{C}$, and protected from light pending flow cytometry analysis. 
Flow cytometry analyses were performed on an FACscan flow cytometer equipped with the CellQuest 3.01 software (BD, San Jose, CA, USA) after acquisition of at least 5000 events within a typical forward and side scatter gate set to exclude dead cells and debris. The results, expressed as means and standard deviations, were the percentage of fluorescing cells or, to assess proliferation, of cells that had undergone cell divisions, that is, with decreased CFSE fluorescence intensity.

\subsection{In Vitro Assessment of an Immunomodulatory Impact of} Purified ELP Protein. In order to determine whether ELP by itself might have an immunomodulatory role, the interaction between ITC-purified ELP and mouse and bovine immune cells was tested in vitro to evaluate lymphocyte proliferation and dendritic cell maturation.

2.4.1. Effect of ELP on Mouse and Bovine Lymphocytes. Mouse spleen cells and bovine PBMC were CFSE stained and stimulated $\left(3 \times 10^{5}\right.$ cells $/$ well $)$ with purified ELP $(5 \mu \mathrm{g} / \mathrm{mL})$ or with the mitogen ConA (positive control, $5 \mu \mathrm{g} / \mathrm{mL}$, Sigma, St. Quentin, France), or left untreated (negative control). Cells were then processed by flow cytometry after 4 days of incubation. Two duplicate experiments were performed in each case.

2.4.2. Effect of ELP on Mouse and Bovine Dendritic Cells. In two duplicate experiments, mBM-DC and Bo-Mo-DC $\left(10^{6}\right.$ cells/well $)$ were stimulated for 24 hours with purified ELP $(2.5$ and $5 \mu \mathrm{g} / \mathrm{mL})$ or left untreated (negative control). The positive control was lipopolysaccharide (LPS, $2 \mu \mathrm{g} / \mathrm{mL}$, Sigma, St. Quentin, France) for mBM-DC and a mix of LPS $(2 \mu \mathrm{g} / \mathrm{mL})$, IFN $\gamma(100 \mathrm{U} / \mathrm{mL}$, Serotec, Cergy, France) and Zymosan $(10 \mu \mathrm{g} / \mathrm{mL}$, Sigma) for Bo-Mo-DC. Cells were then immunostained and phenotyped by flow cytometry to determine the expression of the cell surface markers $(\mathrm{CMH}$ II, CD40, CD80, and CD86).

2.5. Cytotoxicity Evaluation of Tobacco Leaf Extracts (TLEs) from Nontransgenic Plants. This experiment intended to determine whether a crude tobacco leaf extract (TLE) could be used for immunization or exhibit a potential for cytotoxicity.

2.5.1. In Vitro Experiments on Mouse and Bovine Cells. Mouse spleen cells and bovine PBMC $\left(2 \times 10^{6}\right.$ cells $\left./ \mathrm{mL}\right)$ were incubated at $37^{\circ} \mathrm{C}$ for 4 days with TLE dilutions $(\mathrm{v} / \mathrm{v})$ ranging from $0.01 \%$ to $6 \%$. Cells were then processed by flow cytometry for cytotoxicity analysis. Two duplicate experiments were done for each animal.

2.5.2. In Vivo Experiments on Neonate Piglets. To evaluate toxicity, two 10-day-old piglets received 3 intraperitoneal (IP) injections of TLE at days 0,7 , and 14 and 2 control piglets received PBS. The IP route was selected because it is strongly linked to systemic circulation. Samples corresponding to $45 \mathrm{mg}$ of powdered tobacco leaves were used. The TSP concentration ranged from 2 to $2.5 \mathrm{mg} / \mathrm{mL}$. Piglets were thus injected with crude TLE containing $3.6 \mathrm{mg}$ of TSP. Daily clinical observation and temperature recording were performed from day 0 to 21 .

2.6. Evaluation of the Immunogenicity of the Plant-Produced TBAg-ELP Fusion Protein. Mouse experiments were performed with ITC-purified TBAg-ELP, while piglet experiments tested TLE-containing TBAg-ELP fusion protein (TLE-TBAg-ELP).

2.6.1. Mouse Experiments. Five groups of 4 12-week-old C57BL/6 mice were immunized as previously described [55]. Two groups were injected with $5 \mu \mathrm{g}$ or $10 \mu \mathrm{g}$ of TBAg-ELP, two control groups with $5 \mu \mathrm{g}$ or $10 \mu \mathrm{g}$ of $M$. tuberculosis culture filtrate proteins (CFP, Colorado State University, Fort Collins, Colorado, USA), and the negative control group with $0.9 \% \mathrm{NaCl}$. Antigens were delivered with DDA (dimethyldioctadecylammonium bromide, $250 \mu \mathrm{g} /$ dose) and MPL (monophosphoryl lipid A, $25 \mu \mathrm{g} /$ dose) (Sigma, St. Quentin, France) by 3 subcutaneous injections $(200 \mu \mathrm{L})$ on day 0,14 , and 28 . Blood was taken from the tail on day 0 , 42 , and 84 , pooled for each group, and centrifuged to collect sera.

A CFP-ELISA was mounted by coating plates with CFP $(1 \mu \mathrm{g} /$ well $)$, to test sera $(1 / 50)$ in triplicate. Total immunoglobulins (Ig) were detected with HRP-labeled rabbit antimouse polyclonal antibodies (Dako, Trappe, France). Absorbance was measured at $450 \mathrm{~nm}$ after TMB $\left(3,3^{\prime}, 5,5\right.$;Tetramethylbenzidine, Sigma, St. Quentin, France) revelation and $\mathrm{H}_{2} \mathrm{SO}_{4}$ treatment.

A liposome system was tested in a second experiment to deliver and enhance TBAg-ELP immunogenicity. Cationic liposomes were made with DOTAP (N-[1-(2,3dioleoyloxy)propyl]-N,N,N-trimethylammonium chloride, Sigma), downsized by a procedure of freeze/thaw and extrusion (LiposoFast extruder, Avestin, Ottawa, Canada) [56], and mixed with TBAg-ELP. Four groups of 4 mice were immunized, as described above, with $10 \mu \mathrm{g}$ of TBAgELP mixed with DDA/MPL or liposomes $(10 \mu \mathrm{g})$. Controls received $10 \mu \mathrm{g}$ of CFP/DDA/MPL (positive) or $0.9 \% \mathrm{NaCl}$ (negative). Blood sampling and CFP ELISA were as described above. A mouse skin test was also performed on day 56 to evaluate the delayed-type hypersensitivity (DTH) reaction. Mice received $10 \mu \mathrm{g}$ of $M$. bovis-purified protein derivative (PPD, BIOCOR 7090, Pfizer Animal Health) in $40 \mu \mathrm{L}$ of $0.9 \%$ $\mathrm{NaCl}$ by intradermal injection into the right-hind footpad and, as a control, $0.9 \% \mathrm{NaCl}$ in the left-hind footpad. The diameter of the specific swelling was measured 24 hours later and data were expressed as a mean $( \pm S D)$ of the difference between right and left footpads for each group.

2.6.2. Piglet Experiment. Eight piglets were divided into four groups and each group was compared to the other groups allowing a statistical analysis of the difference between groups ( $n=4$, four groups). Group 1 was immunized with E. coli recombinant ESAT-6 (CRBM, Montpellier, France), group 2 with TLE-TBAg-ELP, group 3 with E. coli ESAT-6 and boosted twice with TLE-TBAg-ELP, and group 4 with 
PBS (negative control). Immunized groups received $360 \mu \mathrm{g}$ of antigen by the intradermal route on day 0,7 , and 14 , a dose estimated from a similar study in pigs [20]. For each group, the first two immunizations contained an equal volume of Freund complete adjuvant while the third immunization contained Freund incomplete adjuvant (Sigma, St. Quentin, France). Sera were harvested weekly until the piglets were slaughtered on day 28.

To study porcine IgG responses to ESAT-6 and Ag85B, plates (Maxisorp, Fischer Scientific Bioblock, Illkirsh, France) were coated with E. coli recombinant ESAT-6 or Ag85B (500 ng/mL, carbonate/bicarbonate buffer $0.1 \mathrm{M}, \mathrm{pH}$ 9.6, overnight, $4^{\circ} \mathrm{C}$ ) and blocked (PBS- $0.5 \%$ milk, $1 \mathrm{~h} 30$, $37^{\circ} \mathrm{C}$ ). To assess piglet IgG ability to recognize plantmade TBAg epitopes, plates were coated with rabbit antiAg85B antibodies (U. Conrad; $1: 200$, carbonate/bicarbonate buffer $0.1 \mathrm{M}, \mathrm{pH}$ 9.6, overnight $4^{\circ} \mathrm{C}$ ) and blocked with PBS- $0.5 \%$ milk and TLE containing $2 \mu \mathrm{g} / \mathrm{mL}$ of TBAg-ELP was added to each well $\left(1 \mathrm{~h} 30,37^{\circ} \mathrm{C}\right)$. Sera were tested at $10^{-2}, 10^{-3}$, and $10^{-4}$ in PBS-Tween-1\% BSA and IgG were detected by HRP-conjugated goat antiswine IgG-Fc antibodies ( $1: 20000$, Bethyl, Montgomery, USA). Optical densities were read at $414 \mathrm{~nm}$ after incubation with $2,2^{\prime}$ azino-di-[3-ethylbenzthiazoline-sulfonate].

For immunoblotting, E. coli recombinant ESAT-6 (100 ng) or Ag85B (100 ng) and TLE-TBAg-ELP ( $1 \mu \mathrm{g})$ were run on a $15 \%$ SDS-PAGE, transferred to nitrocellulose membrane, and incubated with piglet sera $(1: 1000$ in PBS-Tween-3\% BSA, 1h30) collected on day 0 and 28. Rabbit ESAT-6 (1:1000) and Ag85B (1:3000) antisera and a cocktail of both for TBAg-ELP were used as positive controls. HRP-conjugated goat antiswine antibodies (1 : 10000, Bethyl, Montgomery, USA) and antirabbit antibodies (1:3000, Dako, Trappe, France) were added (1h30) and revealed by chemiluminescence using the Super Signal West Dura (Pierce, Rockford, USA).

2.7. Statistical Analysis. Statistical analyses were based on the Student's $t$-Test (http://www.physics.csbsju.edu/stats/ttest.html). $P$-values less than .05 were considered significant and less than .01 highly significant. For the piglet experiment, data were analysed by variance analysis using GraphPad Prism software version 3.00 (GraphPad Software Inc., San Diego, CA, USA).

\section{Results}

3.1. Production of Plant-Expressed TBAg-ELP Fusion Protein. The TBAg coding sequence (Figure 1) was inserted into a plant expression cassette as depicted in Figure 2(a). The functionality of the binary vector was verified by transient agro-infiltration and the recombinant proteins were detected by Western blot (data not shown).

Tobacco plants were genetically modified by Agrobacterium-mediated leaf disk transformation and generated plants were screened for accumulation of the ELP fusion protein. Constitutive expression of the TBAg-ELP fusion protein in leaves of $T_{0}$ plants was confirmed by Western

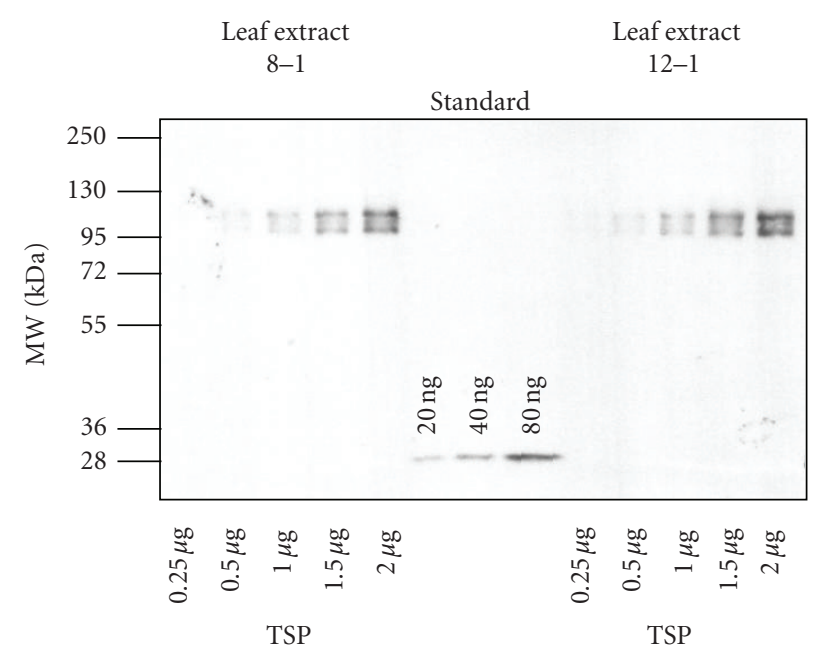

FIgURE 3: Quantification of TBAg-ELP in crude extracts of transgenic tobacco leaves. Dilutions of TLE-TBAg-ELP, from $2 \mu \mathrm{g}$ to $0.25 \mu \mathrm{g}$ of total soluble proteins (TSPs), were separated by reducing $10 \%$ SDS-PAGE, blotted, and immunodetected using an anti-c-myc antibody. Recombinant c-myc-tagged IL- 6 was used as standard. The TBAg-ELP accumulation level was approximately 4\% of TSP of crude leaf extract. Analysed leaf materials came from offspring plant 8 and 12 of the $T_{0}$ plant 26 .

blot using an antibody against the c-myc tag (Figure 2(b)). Fusion to 100xELP resulted in increased accumulation of the TBAg compared to TBAg without ELP fusion (TBAg, $40.8 \mathrm{kDa}$, D. Floss \& U. Conrad unpublished) (Figure 2(b)) as described previously for other recombinant proteins [22-24]. The electrophoretic mobility of ELP fusion was lower than expected ( $84 \mathrm{kDa}$ versus approx. $100 \mathrm{kDa}$, Figures 2(a) and 2(b)) as observed for other ELP fusion proteins expressed in bacteria and plants $[24,57,58]$. TBAg-ELP was detected as a double band, which was probably a result of differences in the $\mathrm{N}$-glycan composition. Indeed, the TBAg aa sequence contains 6 putative glycosylation sites. Transgenic tobacco plants accumulating the recombinant TBAg-ELP had a normal phenotype compared to wild-type plants.

The concentration of TBAg in crude tobacco leaf extracts was estimated by semiquantitative Western blot using dilutions of a defined standard, c-myc-tagged IL-6 (Figure 3). A TBAg-ELP accumulation level of approximately $4 \%$ of total soluble leaf protein was suggested when comparing the intensities of the bands. Since the ELP fusion protein was quantified relative to the unfused standard, the total amount of fusion protein is underestimated.

TBAg-ELP was purified from tobacco leaf material by inverse transition cycling (ITC) $[22,24,29]$ and the resolubilized pellets were analysed by Western blot (data not shown).

3.2. Assessment of an Immunomodulatory Role of the ElastinLike Protein (ELP). As a primary step, since the TBAg was expressed as a fusion protein with the ELP motif, the immunomodulatory effect of ELP was assessed. For this 

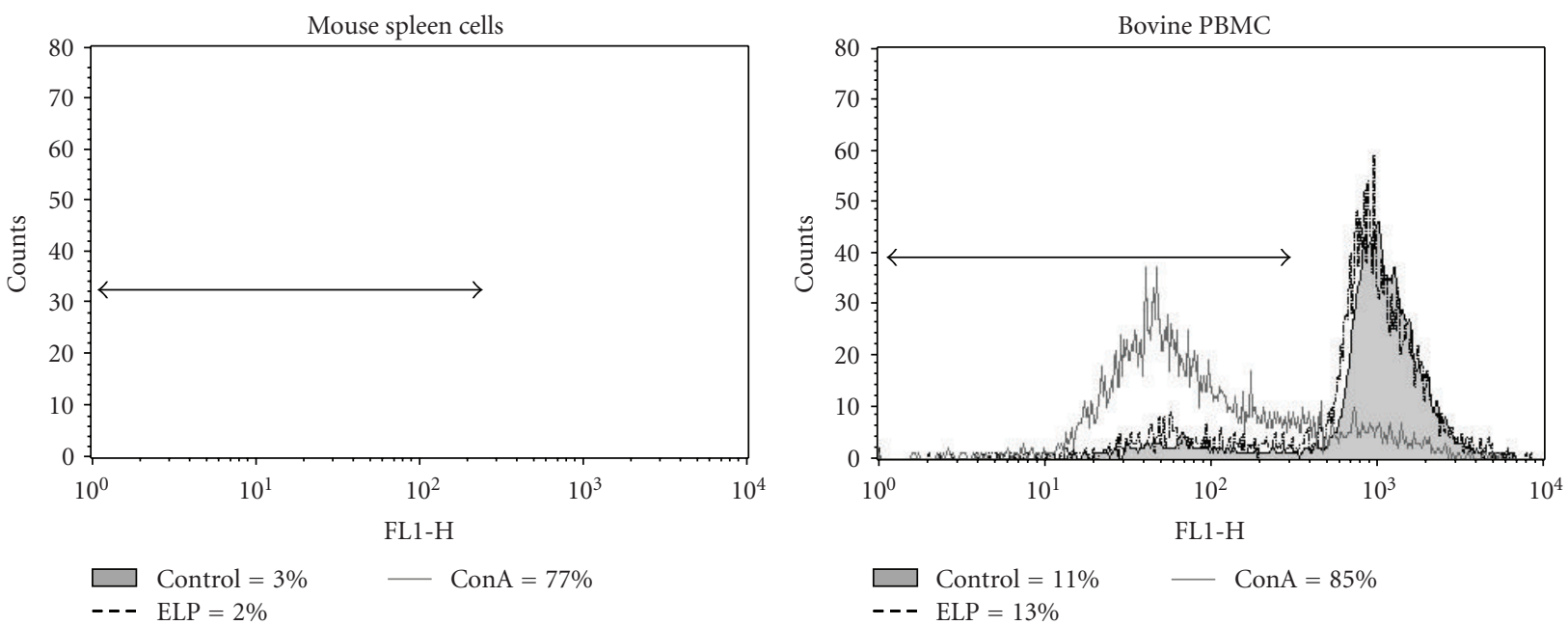

(a)

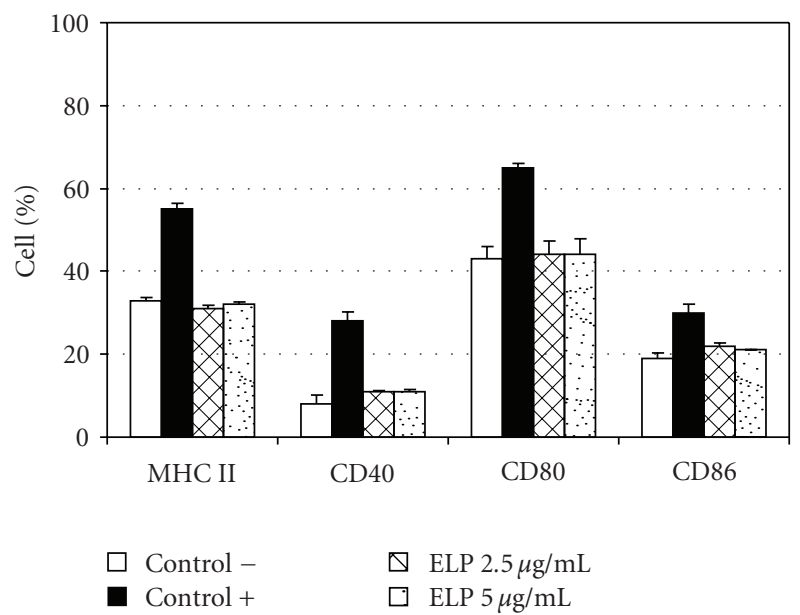

(b)

FIGURE 4: Impact of purified ELP on mouse and bovine immune cells. (a) ELP effect on cell proliferation in mouse spleen cells and bovine PBMC. CFSE-stained mouse spleen cells and bovine PBMC were stimulated for 4 days with $5 \mu \mathrm{g} / \mathrm{mL}$ of purified ELP (ELP) or mitogen ConA (ConA) or left untreated (Control). Cells were then collected and processed by flow cytometry for measurement of proliferating cells. The histograms show the FL1 emission values (FL1-H) for one representative experiment for each animal cell type out of two duplicate experiments. Results are expressed in percentage of cells that had undergone cell divisions, that is, with decreased CFSE fluorescence intensity. The control histogram (unstimulated cells) was filled in grey; the doted black line corresponded to ELP and the grey solid line to ConA stimulation. (b) ELP effect on maturation marker expression in mouse bone marrow-derived dendritic cells (mBM-DCs). Mouse BM-DCs $\left(10^{6}\right.$ cells/well) were stimulated for 24 hours with purified ELP $(2.5$ and $5 \mu \mathrm{g} / \mathrm{mL})$, LPS (control +$)$ or left untreated (control -$)$. Cells were immunostained of the following cell surface markers: CMH II, CD40, CD80, CD86 and processed by flow cytometry as described in Material and Methods. The histogram presents the mean $( \pm S D)$ of the percentages of fluorescing cells for each cell surface marker for two experiments done in duplicate.

purpose, ITC-purified ELP (containing the c-myc tag and KDEL ER retention signal) was used.

The capacity of ELP to induce cell proliferation from mouse spleen cells or bovine PBMC was assayed in two duplicate experiments for each cell type. Figure 4(a) presents the data for one representative experiment for each cell type. The results showed that ConA stimulation (positive control) triggered a strong lymphoproliferation (77\% to $82 \%$ for the mouse spleen cells and $85 \%$ to $87 \%$ for the bovine PBMC) while a low level of proliferating cells was detected in untreated cells (1.5 to $3 \%$ for the mouse cells and $10 \%$ to $11 \%$ for the bovine PBMC). Compared to these data, ELP stimulation did not elicit cell proliferation from mouse spleen cells $(2 \%$ to $2.5 \%)$ nor from bovine cells $(10 \%$ to $13 \%)$.

The effect of purified ELP was also assessed on mouse or bovine dendritic cells (DC), because DC are key players in the immune response. Compared to the negative (untreated cells) and positive (LPS for mBM-DC and LPS/IFN $\gamma /$ zymosan for Bo-Mo-DC) controls, ELP did not 


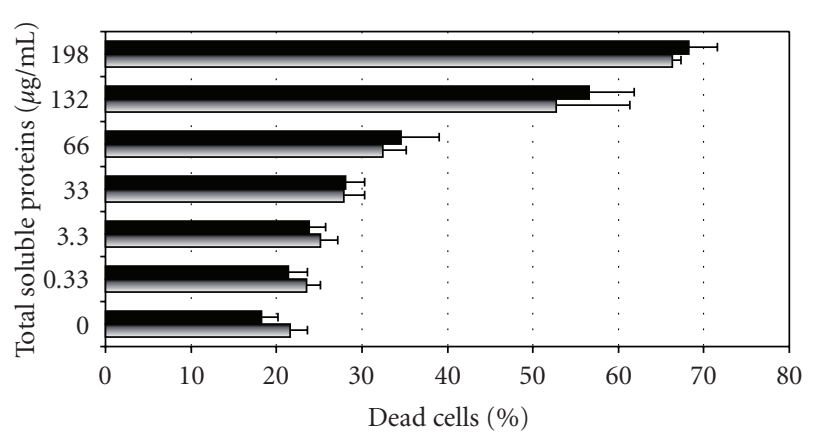

- Mice cells

․ Bovine cells

Figure 5: Assessment of the cytotoxicity of tobacco leaf extracts (TLEs) from nongenetically modified tobacco plants on mouse and bovine cells. TLE was added to mouse spleen cells and to bovine PBMC $\left(2 \times 10^{6}\right.$ cells $\left./ \mathrm{mL}\right)$ with final dilutions ranging from $0.01 \%$ to $6 \%(\mathrm{v} / \mathrm{v})$. The concentration of total soluble proteins (TSPs) in the TLE dilutions was determined by the Bradford assay. The percentage of dead cells was measured 4 days later by flow cytometry after propidium iodide labeling $(2 \mu \mathrm{L})$. The histogram presents the mean percentage $( \pm$ SD) of dead cells ( $X$-axis) induced by each TSP concentration ( $Y$-axis) for each animal cell type.

trigger expression of the maturation markers (MHCII, CD40, CD80, and CD86) on mouse or bovine DC. Figure $4(\mathrm{~b})$ presents the results (mean $\pm \mathrm{SD}$ ) obtained for the mBM-DC in two duplicate experiments. LPS stimulation, compared to untreated cells, elicited an increase of at least $20 \%$ of the expression of the major histocompatibility complex class II molecules (MHC II, 22\%), CD40 (20\%) and CD80 (22\%) and of $11 \%$ for the CD86 expression. Instead, no significant change in the expression of these markers was detected in the presence of 2.5 or $5 \mu \mathrm{g} / \mathrm{mL}$ of ELP. For the Bo-Mo-DC, more variability was observed between the two experiments due to variable basal levels of expression of MHCII, CD40, CD80, and CD86 on untreated cells. This likely results from more heterogeneous DC populations compared to mBM-DC. Nevertheless, in each experiment, ELP stimulation of Bo-Mo-DC, compared to the controls, did not trigger any significant expression of the cell maturation markers.

Since no ELP immunomodulatory effect was detected, the ELP motif should have no impact on TBAg immunogenicity. Consequently, there was no need to remove the 100xELP chain from the plant-expressed TBAg-ELP product.

3.3. Evaluation of the Toxicity of Tobacco Leaf Extracts. To evaluate the potential cytotoxicity of crude tobacco leaf extracts (TLEs), in vitro assays and in vivo experiments in piglets were carried out using nongenetically modified tobacco plants.

3.3.1. In Vitro Experiments on Mouse and Bovine Cells. The mouse spleen cells and bovine PBMC were incubated 4 days with TLE dilutions varying from $0.01 \%$ to $6 \%$. The concentration of total soluble proteins (TSPs) in the TLE ranged from $0.33 \mu \mathrm{g} / \mathrm{mL}$ in the $0.01 \%$ dilution to $198 \mu \mathrm{g} / \mathrm{mL}$ in the $6 \%$ dilution. A dose-dependent toxicity on both animal cells was observed in the presence of TLE as shown in Figure 5. The results are expressed as the mean percentage of dead cells $( \pm S D)$, measured for each TLE dilution, from 2 experiments performed in duplicate. Up to a concentration of $66 \mu \mathrm{g} / \mathrm{mL}$ of TSP (2\% TLE), the mean percentage of dead cells slightly increased from $18.23 \% \pm 1.98 \%$ for the murine cells and $21.55 \% \pm 2.11 \%$ for the bovine cells without TLE to $34.61 \% \pm 4.38 \%$ and $32.48 \% \pm 2.74 \%$, respectively, for a $2 \%$ dilution. For TLE dilutions corresponding to higher concentrations of TSP (132 and $198 \mu \mathrm{g} / \mathrm{mL}$ ), the mean percentage of dead cells strongly increased, reaching $68.24 \%$ $( \pm 3.35 \%)$ for the murine cells and $66.31 \%( \pm 1.03 \%)$ for the bovine cells for the $6 \%$ dilution.

Considering the cytotoxicity induced by the tobacco leave soluble extract, ITC-purified TBAg-ELP was used for evaluation of the plant-expressed TBAg immunogenicity in mice. Indeed, for TBAg-transgenic tobacco plants, the ratio $\mathrm{TBAg} / \mathrm{TSP}$ was estimated to be $4 \%$. Therefore, the TSP doses required to immunize mice with 5 to $10 \mu \mathrm{g}$ of TBAg would be, respectively, 125 and $250 \mu \mathrm{g}$ of TSP from TBAg-transgenic plants. However, our results suggested that, after 4 days of contact, these doses of tobacco soluble proteins can induce cytotoxicity in half to two third of the initial cell population.

3.3.2. In Vivo Experiments on Neonate Piglets. The TLE clinical impact was assessed by injecting neonate piglets with TLE containing $3.6 \mathrm{mg}$ of TSP. In this experiment, neonate piglets were used to increase sensitivity to TLEs toxicity. In contrast to the in vitro data, the in vivo experiment showed no significant change in piglet temperature or clinical status after three intraperitoneal injections (data not shown). Accordingly, to assess plant-expressed TBAg immunogenicity in the piglet model, crude TLE from TBAgELP-transgenic tobacco plants was used.

\subsection{In Vivo Immunogenicity Evaluation of the Plant-Expressed TBAg-ELP Fusion Protein}

3.4.1. Mouse Experiments. The first experiment set out to evaluate the clinical impact and immunogenicity of the plant-expressed ITC-purified TBAg-ELP compared, as a positive control, to $M$. tuberculosis CFP. The anti-CFP humoral response was tested to assess the ability of the TBAg-ELP-induced antibodies to recognize the native $M$. tuberculosis ESAT- 6 and Ag85B contained in the CFP.

None of the immunized mice developed any clinical side effects. The two groups of CFP-immunized mice exhibited a strong anti-CFP dose-dependant humoral response detected on day 42 and lasting up to day 84 , compared to the control group (Figure 6, upper graph). The group of mice receiving $10 \mu \mathrm{g}$ of TBAg-ELP, but not $5 \mu \mathrm{g}$, was also characterized by an anti-CFP antibody response with a peak observed on day 42 (Figure 6, lower graph). The immunogenicity of the plant-expressed TBAg was revealed by its ability to trigger TBAg-specific antibodies able to recognize the native M. tuberculosis ESAT-6 and Ag85B. The difference in the 


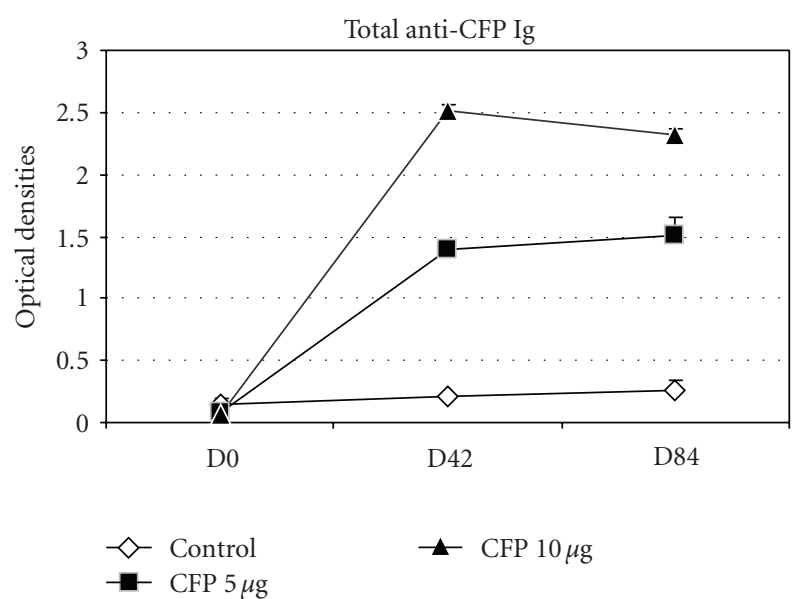

(a)

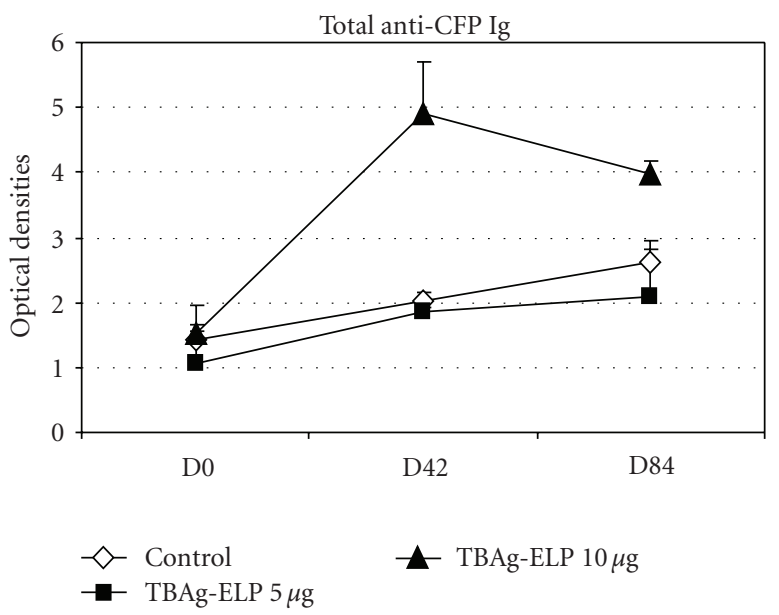

(b)

Figure 6: Kinetic of the anti-CFP humoral response from CFP and TBAg-immunized mice. Five groups of 4 mice were analysed. Two positive groups were injected with 5 and $10 \mu$ g of CFP (upper graph) while the negative control group received $0.9 \% \mathrm{NaCl}$ (both graphs). Two other groups were immunized with 2 doses (5 and $10 \mu \mathrm{g}$ ) of purified TBAg-ELP (lower graph). Antigens were delivered in DDA/MPL by $3 \mathrm{SC}$ injections on day 0,14 , and 28 . Blood samples were taken on day 0,42 , and 84 and pooled. The anti-CFP response was analysed by ELISA using plates coated with $1 \mu \mathrm{g} /$ well of CFP. Diluted sera $(1 / 50)$ were tested in triplicate. Total Igs were detected with HRP-labeled rabbit antimouse Ig antibodies. Absorbance was measured at $450 \mathrm{~nm}$ after TMB revelation and $\mathrm{H}_{2} \mathrm{SO}_{4}$ treatment. Results are presented as mean \pm standard deviation (SD).

intensity level of CFP-induced and TBAg-induced antibodies was due to the multiple proteins contained within the CFP, while only ESAT-6 and Ag85B were present in the TBAg-ELP. The reduced intensity and short duration of the antibody response showed the need for an antigen delivery system able to enhance the immune response.

To that end, a cationic liposome-based delivery system was tested. None of the mice showed any clinical signs. The anti-CFP humoral response detected for the TBAg-ELP and

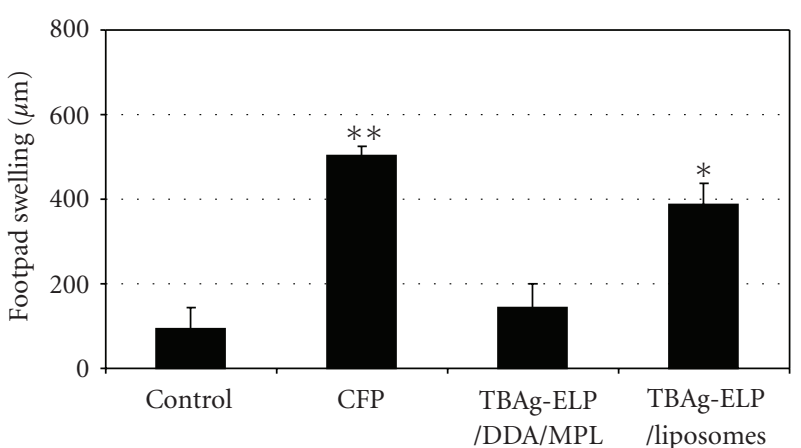

FIGURE 7: Delayed-type hypersensitivity response in TBAg-ELP and CFP-immunized mice. Groups of 4 mice were immunized, as described above, with $10 \mu \mathrm{g}$ of TBAg-ELP mixed with DDA/MPL or loaded in liposomes. The positive control group was injected with $10 \mu \mathrm{g}$ of CFP/DDA/MPL and the negative control group with $0.9 \% \mathrm{NaCl}$. A skin test was performed on each animal on day 56 to evaluate the delayed-type hypersensitivity (DTH) reaction. Mice received an intradermal injection of $10 \mu \mathrm{g}$ of $M$. bovis PPD (in $40 \mu \mathrm{L}$ of $0.9 \% \mathrm{NaCl}$ ) into the right-hind footpad and, as a control, $0.9 \% \mathrm{NaCl}$ into the left-hind footpad. The diameter of the specific swelling was measured $24 \mathrm{~h}$ later and data were expressed as the mean $( \pm \mathrm{SD})$ of the difference between right and left footpads for each group of mice $(n=4)$. The statistical analysis compared (1) the CFP group versus the negative control group and (2) the TBAg/liposome group versus the TBAg/DDA/MPL group and the negative control group. $P$-values less than .05 were considered significant $(*)$ and less than .01 highly significant $(* *)$.

CFP mice groups was similar to the one observed in the first experiment. No significant change was noticed for the $10 \mu \mathrm{g}$ of TBAg-ELP whether in liposomes or in DDA/MPL (data not shown).

The tuberculin skin test was carried out, as indicative of the TBAg-induced cellular immune response. Similar to the CFP ELISA, this test was performed with PPD containing native mycobacterial proteins. Although the DTH response was moderate, it revealed the significant increase $(P<.05)$ in TBAg-ELP-primed lymphocytes on day 56 with liposome delivery compared to DDA/MPL (Figure 7). The CFP-immunized mice were characterized by a highly significant DTH response $(P<.01)$. The diameter of the footpad swelling in the CFP group reached $503 \pm 22 \mu \mathrm{m}$, while it was $388 \pm 51 \mu \mathrm{m}$ for TBAg-ELP/liposome group and only $143 \pm 58 \mu \mathrm{m}$ for the TBAg-ELP/DDA/MPL or $95 \pm$ $50 \mu \mathrm{m}$ for the negative control groups.

3.4.2. Piglet Experiment. The immunogenicity of the TBAgELP transgenic tobacco leaf crude extract (TLE-TBAg-ELP) was assessed in comparison to E. coli recombinant ESAT-6 protein. In this experiment, the piglets older (33-61 days old) than the neonates piglets, used for the toxicity assay, were selected because of the maturity of their immune system.

ELISA analyses showed that injections with purified recombinant ESAT-6 alone (group 1) induced an IgG antibody response to ESAT- 6 while injections of TLE-TBAg-ELP 


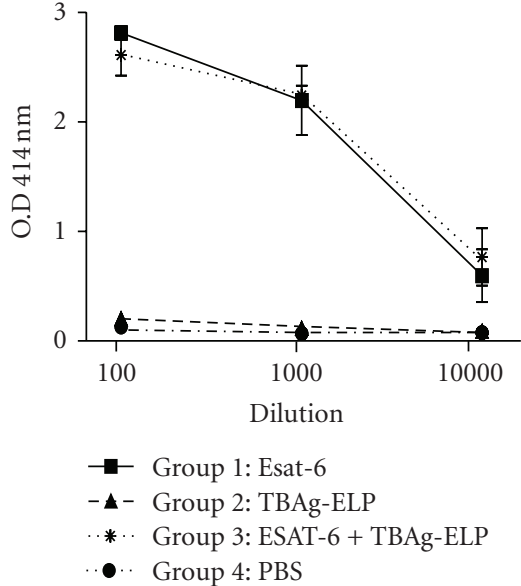

ESAT-6 ELISA

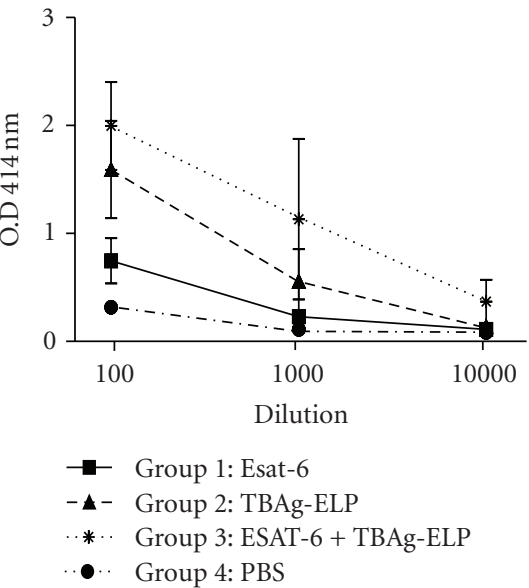

Ag85B ELISA

(a)

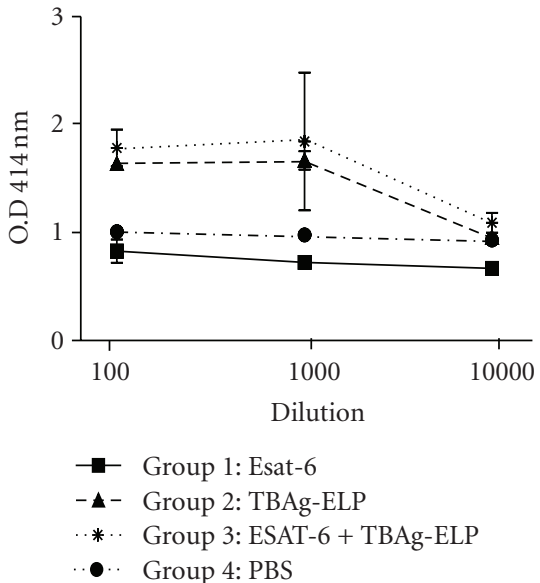

TBAg-ELP ELISA

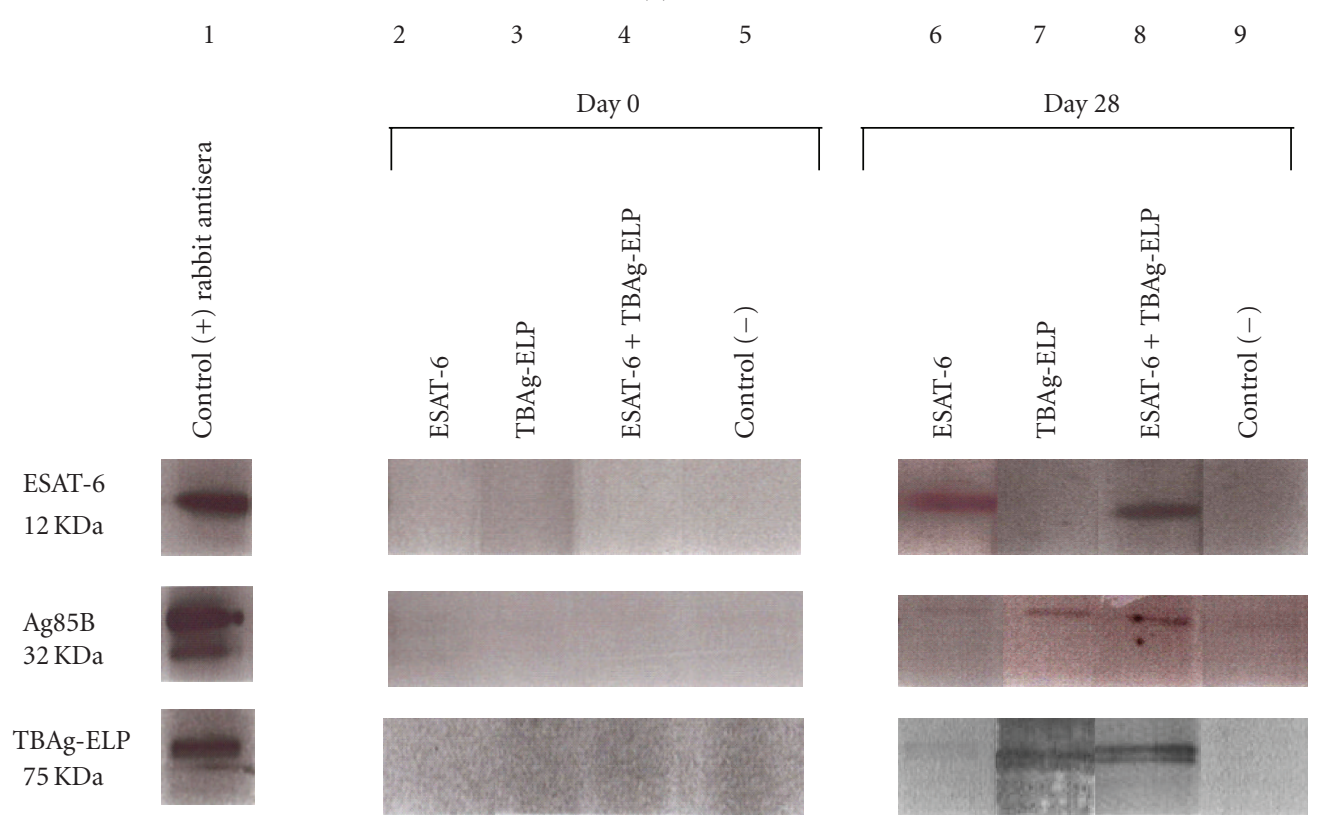

(b)

FiguRE 8: Assessment of the humoral response during the piglet experiment. Four groups of 2 piglets were immunized on days 0 , 7 , and 14 through an intradermal route. Group 1 was injected with E. coli ESAT-6, group 2 with TLE-TBAg-ELP, group 3 with E. coli ESAT-6 and boosted two times with TLE-TBAg-ELP, and group 4 received PBS, as the control. Sera were harvested weekly and diluted $\left(10^{-2}, 10^{-3}\right.$, and $\left.10^{-4}\right)$. The IgG antibody response against the different TB antigens was measured by ELISA (a) and Western blot (b). (a) ELISA analysis of the piglet IgG response on day 28 against E. coli ESAT-6, Ag85B, and plant-expressed TBAg-ELP. Results represent the mean optical densities ( \pm SEM, $n=2$, each in triplicate). (b) Western blot analysis of the piglet antibody response on day 0 and 28 . Lane 1 : rabbit antisera, lanes 2 and 6: sera from piglets immunized with E. coli ESAT-6 (group 1), lanes 3 and 7: sera from piglets immunized with TLE-TBAg-ELP (group 2), lanes 4 and 8: sera from piglets sensitized with E. coli ESAT-6 and boosted with TLE-TBAg-ELP (group 3), and lanes 5 and 9: sera from control piglets receiving PBS (group 4).

(group 2) induced an $\operatorname{IgG}$ antibody response to Ag85B only (Figure $8(\mathrm{a})$ ). However, sensitization with bacterial ESAT-6 and boosting with the TLE-TBAg-ELP (group 3) induced an IgG response to both ESAT-6 and Ag85B (Figure $8(\mathrm{a})$ ).

Western blot analysis (Figure $8(\mathrm{~b})$ ) gave much the same data showing that results were independent of antigen conformation. Thus, immunization with TLE-TBAg-ELP was not sufficient to induce an antibody response against both antigens, showing that ESAT-6 sensitization is essential.

In both experiments (ELISA and Western blot), control piglets immunized with PBS and Freund adjuvant neither elicited any antibody response against ESAT-6, Ag85B nor toward TLE-TBAg-ELP. This result showed that the antibody responses detected in piglets from group 1, 2, and 3 were antigen specific. 


\section{Discussion}

This study explored the possibility of genetically engineering plants to produce mycobacterial antigens for the development of a subunit vaccine against tuberculosis (TB). In order to achieve this, fusion to the elastin-like peptides (ELP) was the strategy adopted for the plant expression system. The findings showed that the ELP fusion technology led to an efficient and stable expression of the mycobacterial Ag85BESAT-6 proteins, as an ELP fusion in tobacco plants, while maintaining normal growth and morphology. The level of production for this TBAg-ELP fusion protein reached $4 \%$ of the tobacco leaf total soluble proteins (TSP) for the best producer plants. The plant-expressed TBAg-ELP fusion protein was targeted to the lumen of the ER because higher accumulation of secreted recombinant proteins is reported in that intracellular compartment [28]. The ELP expression system had proved its efficacy since commonly lower levels of foreign proteins accumulate in plants $[14,59]$. However, with certain expression systems and conditions, expression levels of plant-made foreign protein have been reported to achieve $20 \%$ and more TSP [14, 17]. Nevertheless, a previous study expressing ESAT-6 in Nicotiana tabacum using a viral vector mentioned levels ranging from $0.5 \%$ to $1 \%$ of TSP [60].

The immunogenicity and the safety of the plantexpressed TBAg were compared and confirmed in both mouse and piglet models. Mice were used as a reference laboratory model and compared to piglets that were used as a preclinical model of human vaccination, based on similarities between swine and human immune responses. Bovine TB was also an objective; however, no small animal model can replace bovine. With cost constraints being a limiting factor for in vivo cattle studies, only in vitro experiments with bovine immune cells were carried out. Mice and piglets injected with purified TBAg-ELP or with crude tobacco leaf extracts (TLE), respectively, exhibited a mycobacterial-specific immune response with no side effects.

In mice, the immunogenicity of plant-purified TBAgELP was evaluated and compared to two immunogenic preparations of native $M$. tuberculosis proteins, namely, CFP (culture filtrate proteins) and PPD (purified protein derivatives). Our findings demonstrated that both the TBAginduced antibodies and primed T-cells were able to recognize the native proteins contained in the mycobacterial CFP or PPD. Ag85 is a prominent component of these preparations and ESAT-6 is also present in significant proportion [61]. Hence, the antibody and T-cell reactivity might be predominantly directed against Ag85B but possibly also against ESAT-6.

In piglets, the immunogenicity of crude extracts of TBAg-ELP transgenic tobacco leaves (TLE-TBAg-ELP) was assessed. The piglet humoral response was analysed by Western blot and by using three ELISAs, based on E. coli ESAT-6, E. coli Ag85B, and TLE containing TBAg-ELP, respectively. The results revealed the main reactivity of the TLE-TBAg-ELP-induced antibodies against Ag85B. Indeed, the piglet antibodies only recognized the plant-produced TBAg-ELP and E. coli Ag85B.
The findings in the two animal models confirm the maintenance of bacterial Ag85B B-cell epitopes in the TBAg fusion protein produced by the tobacco plants.

In contrast, the absence of E. coli ESAT-6 recognition by the TLE-TBAg-ELP-immunized piglet sera (group 2) and of the ESAT- 6 within the plant-expressed TBAg by the E. coli ESAT-6-injected piglet sera (group 1) suggested a difference in B-cell epitopes between bacterial and plantexpressed ESAT-6. This difference should not result from the TBAg gene cassette since it was designed to respect the protein sequence. Moreover, in Western blot analysis under denatured conditions, the plant-expressed TBAg-ELP reacted with rabbit anti-E. coli ESAT-6 antisera (data not shown). Consequently, linear ESAT-6 B-epitope sequences were conserved after plant expression. Nevertheless, within the transgenic tobacco leaf extract (TLE-TBAg-ELP), ESAT-6 was located between Ag85B and ELP. Expression and folding of one of these two proteins might hide part of ESAT-6, thus hindering antibody production in piglets.

Cell-mediated responses are known to play a key role in human and bovine $\mathrm{TB}[7,62,63]$. To address this point, the mouse model and the delayed hypersensitivity test (DTH), which correlates with the frequency of mycobacteriaprimed T-cells, were used [64-66]. Our findings showed that the plant-produced TBAg-ELP was able to trigger a Tcell response in mice, probably of the CD4 T-cell subtype. The higher frequency of TBAg-primed T-cells observed with the liposome delivery system probably resulted from more efficient TBAg interaction with the host antigenpresenting cells. The DTH response to PPD confirmed the TBAg-primed T-cell ability to recognize native mycobacterial proteins. Ag85B is probably the main target but ESAT- 6 should be involved too. ESAT- 6 is, indeed, also a T-cell immunogen and contains overlapping B- and T-cell epitopes [67]. Furthermore, Rigano and colleagues [68] reported the induction of a CD4 T-cell immune response by feeding mice with an Arabidopsis-made ESAT-6 fused to the E. coli heatlabile enterotoxin (LTB).

Our results thus showed the expression of an Ag85BESAT-6 fusion protein in leaves of transgenic tobacco plants able to trigger host antibodies and T-cells recognizing mycobacterial Ag85B and probably ESAT-6.

Production of a subunit vaccine against tuberculosis in plants might be a promising strategy to overcome the cost constraints linked to large vaccination campaigns, mainly in developing countries where such vaccines are needed the most. Indeed, plants can be used as cost-effective biofactories for foreign protein production but also, for food plants, as efficient oral antigen delivery system [15, 17]. It has been estimated that proteins can be produced in plants at a cost 10-50-fold less than in E. coli [22]. Nevertheless, several challenges still need to be overcome before plantbased vaccines become more widely available $[16,17]$. Environmental concern and public acceptance are major ones. However, glasshouse-based plant production, rather than in open fields, might resolve this problem. To that end, high levels of foreign protein expression and consistency of those expression levels will allow cost effective production in contained facilities. The ELP fusion technology provides 
many advantages for large-scale production of biologicals [32]. This includes increased yields [21-23] and simple downstream processing by inverse transition cycling $[22,24$, $27,29]$. Our study confirmed that ELP has no immunomodulating activity. This finding is in accordance with the lack of immunogenicity already described for ELP, its biodegradability and biocompatibility for human tissues, tissue fluids, and blood [33, 69]. Fusion of a protein to ELP can also promote particle aggregation. This thermally responsive ELP strategy might lead to interesting delivery systems, able to form a depot effect into a target compartment with sustained release of the antigens [70].

In conclusion, this study presents the first results of an efficient plant-expression system, relying on the elastin-like peptide fusion strategy, to produce a safe and immunogenic mycobacterial Ag85B-ESAT-6 fusion protein as a potential vaccine candidate against TB.

\section{Acknowledgments}

This work was mainly supported by an EU FP6-funded project entitled "PHARMA-PLANTA: Recombinant pharmaceuticals from plants for human health," Project no. LSHB-CT-2003-503565 and was also part of the EU FP6funded EPIZONE Network. We thank the TB Research Materials and Vaccine Testing Contract at Colorado State University for supply of the TB reagents, J. C. Breitler for providing nongenetically modified tobacco plant leaves and relevant advice, and P. Biggins for English reviewing. We also acknowledge the skilful technical assistance of N. Richard, T. Macotta, C. Helmold, and I. Tillack.

\section{References}

[1] E. Etter, P. Donado, F. Jori, A. Caron, F. Goutard, and F. Roger, "Risk analysis and bovine tuberculosis, a re-emerging zoonosis," Annals of the New York Academy of Sciences, vol. 1081, pp. 61-73, 2006.

[2] J. C. Hope and B. Villarreal-Ramos, "Bovine TB and the development of new vaccines," Comparative Immunology, Microbiology and Infectious Diseases, vol. 31, no. 2-3, pp. 77100, 2008.

[3] I. N. de Kantor, M. Ambroggi, S. Poggi, et al., "Human Mycobacterium bovis infection in ten Latin American countries," Tuberculosis, vol. 88, no. 4, pp. 358-365, 2008.

[4] M. J. Wilkins, J. Meyerson, P. C. Bartlett, et al., "Human Mycobacterium bovis infection and bovine tuberculosis outbreak, Michigan, 1994-2007," Emerging Infectious Diseases, vol. 14, no. 4, pp. 657-660, 2008.

[5] R. G. Hewinson, H. M. Vordermeier, and B. M. Buddle, "Use of the bovine model of tuberculosis for the development of improved vaccines and diagnostics," Tuberculosis, vol. 83, no. 1-3, pp. 119-130, 2003.

[6] I. Van Rhijn, J. Godfroid, A. Michel, and V. Rutten, "Bovine tuberculosis as a model for human tuberculosis: advantages over small animal models," Microbes and Infection, vol. 10, no. 7, pp. 711-715, 2008.

[7] P. Andersen and T. M. Doherty, "The success and failure of BCG_-implications for a novel tuberculosis vaccine," Nature Reviews Microbiology, vol. 3, no. 8, pp. 656-662, 2005.
[8] A. W. Olsen, A. Williams, L. M. Okkels, G. Hatch, and P. Andersen, "Protective effect of a tuberculosis subunit vaccine based on a fusion of antigen $85 \mathrm{~B}$ and ESAT- 6 in the aerosol guinea pig model," Infection and Immunity, vol. 72, no. 10, pp. 6148-6150, 2004.

[9] P. Andersen, "Tuberculosis vaccines-an update," Nature Reviews Microbiology, vol. 5, no. 7, pp. 484-487, 2007.

[10] E. M. Agger, I. Rosenkrands, A. W. Olsen, et al., "Protective immunity to tuberculosis with Ag85B-ESAT-6 in a synthetic cationic adjuvant system IC31," Vaccine, vol. 24, no. 26, pp. 5452-5460, 2006.

[11] L. H. Ly and D. N. McMurray, "Tuberculosis: vaccines in the pipeline," Expert Review of Vaccines, vol. 7, no. 5, pp. 635-650, 2008.

[12] R. I. Curtiss and C. A. Cardineau, "Oral immunization by transgenic plants," World Patent Application WO 90/02484, 1990.

[13] H. S. Mason, D. M.-K. Lam, and C. J. Arntzen, "Expression of hepatitis B surface antigen in transgenic plants," Proceedings of the National Academy of Sciences of the United States of America, vol. 89, no. 24, pp. 11745-11749, 1992.

[14] D. M. Floss, D. Falkenburg, and U. Conrad, "Production of vaccines and therapeutic antibodies for veterinary applications in transgenic plants: an overview," Transgenic Research, vol. 16, no. 3, pp. 315-332, 2007.

[15] S. J. Streatfield, "Mucosal immunization using recombinant plant-based oral vaccines," Methods, vol. 38, no. 2, pp. 150157, 2006.

[16] V. Yusibov and S. Rabindran, "Recent progress in the development of plant-derived vaccines," Expert Review of Vaccines, vol. 7, no. 8, pp. 1173-1183, 2008.

[17] Y. Thanavala, Z. Huang, and H. S. Mason, "Plant-derived vaccines: a look back at the highlights and a view to the challenges on the road ahead," Expert Review of Vaccines, vol. 5, no. 2, pp. 249-260, 2006.

[18] O. Guerrero-Andrade, E. Loza-Rubio, T. Olivera-Flores, T. Fehérvári-Bone, and M. A. Gómez-Lim, "Expression of the Newcastle disease virus fusion protein in transgenic maize and immunological studies," Transgenic Research, vol. 15, no. 4, pp. 455-463, 2006.

[19] A. Khandelwal, G. Lakshmi Sita, and M. S. Shaila, "Oral immunization of cattle with hemagglutinin protein of rinderpest virus expressed in transgenic peanut induces specific immune responses," Vaccine, vol. 21, no. 23, pp. 3282-3289, 2003.

[20] T. Tuboly, W. Yu, A. Bailey, et al., "Immunogenicity of porcine transmissible gastroenteritis virus spike protein expressed in plants," Vaccine, vol. 18, no. 19, pp. 2023-2028, 2000.

[21] J. Patel, H. Zhu, R. Menassa, L. Gyenis, A. Richman, and J. Brandle, "Elastin-like polypeptide fusions enhance the accumulation of recombinant proteins in tobacco leaves," Transgenic Research, vol. 16, no. 2, pp. 239-249, 2007.

[22] J. Scheller, D. Henggeler, A. Viviani, and U. Conrad, "Purification of spider silk-elastin from transgenic plants and application for human chondrocyte proliferation," Transgenic Research, vol. 13, no. 1, pp. 51-57, 2004.

[23] J. Scheller, M. Leps, and U. Conrad, "Forcing single-chain variable fragment production in tobacco seeds by fusion to elastin-like polypeptides," Plant Biotechnology Journal, vol. 4, no. 2, pp. 243-249, 2006.

[24] D. M. Floss, M. Sack, J. Stadlmann, et al., "Biochemical and functional characterization of anti-HIV antibody-ELP fusion proteins from transgenic plants," Plant Biotechnology Journal, vol. 6 , no. 4 , pp. 379-391, 2008. 
[25] D. M. Floss, M. Sack, E. Arcalis, et al., "Influence of elastin-like peptide fusions on the quantity and quality of a tobacco-derived human immunodeficiency virus-neutralizing antibody," Plant Biotechnology Journal, vol. 7, no. 9, pp. 899913, 2009.

[26] B. Li and V. Daggett, "Molecular basis for the extensibility of elastin," Journal of Muscle Research and Cell Motility, vol. 23, no. 5-6, pp. 561-573, 2002.

[27] D. E. Meyer and A. Chilkoti, "Purification of recombinant proteins by fusion with thermally-responsive polypeptides," Nature Biotechnology, vol. 17, no. 11, pp. 1112-1115, 1999.

[28] A. J. Conley, J. J. Joensuu, A. M. Jevnikar, R. Menassa, and J. E. Brandle, "Optimization of elastin-like polypeptide fusions for expression and purification of recombinant proteins in plants," Biotechnology and Bioengineering, vol. 103, no. 3, pp. 562-573, 2009.

[29] M. Lin, S. Rose-John, J. Grotzinger, U. Conrad, and J. Scheller, "Functional expression of a biologically active fragment of soluble gp130 as an ELP-fusion protein in transgenic plants: purification via inverse transition cycling," Biochemical Journal, vol. 398, no. 3, pp. 577-583, 2006.

[30] J. C. Rodriguez-Cabello, S. Prieto, J. Reguera, F. J. Arias, and A. Ribeiro, "Biofunctional design of elastin-like polymers for advanced applications in nanobiotechnology," Journal of Biomaterials Science, Polymer Edition, vol. 18, no. 3, pp. 269286, 2007.

[31] D. Raucher, I. Massodi, and G. L. Bidwell III, "Thermally targeted delivery of chemotherapeutics and anti-cancer peptides by elastin-like polypeptide," Expert Opinion on Drug Delivery, vol. 5, no. 3, pp. 353-369, 2008.

[32] D. M. Floss, K. Schallau, S. Rose-John, U. Conrad, and J. Scheller, "Elastin-like polypeptides revolutionize recombinant protein expression and their biomedical application," Trends in Biotechnology, vol. 28, no. 1, pp. 37-45, 2010.

[33] D. W. Urry, T. M. Parker, M. C. Reid, and D. C. Gowda, "Biocompatibility of the bioelastic materials, poly(GVGVP) and its $\gamma$-irradiation cross-linked matrix: summary of generic biological test results," Journal of Bioactive and Compatible Polymers, vol. 6, no. 3, pp. 263-282, 1991.

[34] A. Chilkoti, T. Christensen, and J. A. MacKay, "Stimulus responsive elastin biopolymers: applications in medicine and biotechnology," Current Opinion in Chemical Biology, vol. 10, no. 6, pp. 652-657, 2006.

[35] Y. Nakamura, T. Gojobori, and T. Ikemura, "Codon usage tabulated from international DNA sequence databases: status for the year 2000," Nucleic Acids Research, vol. 28, no. 1, p. 292, 2000.

[36] N. Bohorova, R. Frutos, M. Royer, et al., "Novel synthetic Bacillus thuringiensis cry $1 B$ gene and the cry $1 B$-cry $1 A b$ translational fusion confer resistance to southwestern corn borer, sugarcane borer and fall armyworm in transgenic tropical maize," Theoretical and Applied Genetics, vol. 103, no. 6-7, pp. 817-826, 2001.

[37] J.-C. Breitler, V. Marfà, M. Royer, et al., "Expression of a Bacillus thuringiensis cry $1 B$ synthetic gene protects Mediterranean rice against the striped stem borer," Plant Cell Reports, vol. 19, no. 12, pp. 1195-1202, 2000.

[38] G. W. Almond, "Research applications using pigs," The Veterinary Clinics of North America. Food Animal Practice, vol. 12, no. 3, pp. 707-716, 1996.

[39] C. A. Bolin, D. L. Whipple, K. V. Khanna, J. M. Risdahl, P. K. Peterson, and T. W. Molitor, "Infection of swine with Mycobacterium bovis as a model of human tuberculosis,"
Journal of Infectious Diseases, vol. 176, no. 6, pp. 1559-1566, 1997.

[40] C. Prodromou and L. H. Pearl, "Recursive PCR: a novel technique for total gene synthesis," Protein Engineering, vol. 5, no. 8, pp. 827-829, 1992.

[41] A. Franck, H. Guilley, G. Jonard, K. Richards, and L. Hirth, "Nucleotide sequence of cauliflower mosaic virus DNA," Cell, vol. 21, no. 1, pp. 285-294, 1980.

[42] J. T. Odell, F. Nagy, and N.-H. Chua, "Identification of DNA sequences required for activity of the cauliflower mosaic virus 35S promoter," Nature, vol. 313, no. 6005, pp. 810-812, 1985.

[43] H. Bäumlein, U. Wobus, J. Pustell, and F. C. Kafatos, "The legumin gene family: structure of a B type gene of Vicia faba and a possible legumin gene specific regulatory element," Nucleic acids research, vol. 14, no. 6, pp. 2707-2720, 1986.

[44] S. Munro and H. R. B. Pelham, "An hsp70-like protein in the ER: identity with the $78 \mathrm{kd}$ glucose-regulated protein and immunoglobulin heavy chain binding protein," Cell, vol. 46, no. 2, pp. 291-300, 1986.

[45] M. Gahrtz and U. Conrad, "Immunomodulation of plant function by in vitro selected single-chain Fv intrabodies," in Methods in Molecular Biology: Recombinant Proteins from Plants, L. Faye and V. Gomord, Eds., pp. 289-312, Humana Press, Totowa, NJ, USA, 2009.

[46] C. Xiang, P. Han, I. Lutziger, K. Wang, and D. J. Oliver, "A mini binary vector series for plant transformation," Plant Molecular Biology, vol. 40, no. 4, pp. 711-717, 1999.

[47] R. Deblaere, B. Bytebier, H. De Greve, et al., "Efficient octopine Ti plasmid-derived vectors for Agrobacterium-mediated gene transfer to plants," Nucleic Acids Research, vol. 13, no. 13, pp. 4777-4788, 1985.

[48] J. Kapila, R. De Rycke, M. Van Montagu, and G. Angenon, “An Agrobacterium-mediated transient gene expression system for intact leaves," Plant Science, vol. 122, no. 1, pp. 101-108, 1997.

[49] C. Vaquero, M. Sack, J. Chandler, et al., "Transient expression of a tumor-specific single-chain fragment and a chimeric antibody in tobacco leaves," Proceedings of the National Academy of Sciences of the United States of America, vol. 96, no. 20, pp. 11128-11133, 1999.

[50] R. B. Horsch, J. E. Fry, N. L. Hoffmann, D. Eichholtz, S. G. Rogers, and R. T. Fraley, "A simple and general method for transferring genes into plants," Science, vol. 227, no. 4691, pp. 1229-1230, 1985.

[51] T. Murashige and F. Skoog, "A revised medium for rapid growth and bio assays with tobacco tissue cultures," Physiologia Plantarum, vol. 15, pp. 473-497, 1962.

[52] K. Inaba, M. Inaba, N. Romani, et al., "Generation of large numbers of dendritic cells from mouse bone marrow cultures supplemented with granulocyte/macrophage colonystimulating factor," Journal of Experimental Medicine, vol. 176, no. 6, pp. 1693-1702, 1992.

[53] L. Dedieu, E. Chapey, and V. Balcer-Rodrigues, "Mycoplasma mycoides ssp. mycoides biotype small colony-secreted components induce apoptotic cell death in bovine leucocytes," Scandinavian Journal of Immunology, vol. 62, no. 6, pp. 528538, 2005.

[54] J. C. Hope, D. Werling, R. A. Collins, B. Mertens, and C. J. Howard, "Flt-3 ligand, in combination with bovine granulocyte-macrophage colony- stimulating factor and interleukin-4, promotes the growth of bovine bone marrow derived dendritic cells," Scandinavian Journal of Immunology, vol. 51, no. 1, pp. 60-66, 2000. 
[55] A. W. Olsen, L. A. H. Van Pinxteren, L. M. Okkels, P. B. Rasmussen, and P. Andersen, "Protection of mice with a tuberculosis subunit vaccine based on a fusion protein of antigen 85B and ESAT-6," Infection and Immunity, vol. 69, no. 5, pp. 2773-2778, 2001.

[56] R. C. MacDonald, R. I. MacDonald, B. P. M. Menco, K. Takeshita, N. K. Subbarao, and L.-R. Hu, "Small-volume extrusion apparatus for preparation of large, unilamellar vesicles," Biochimica et Biophysica Acta, vol. 1061, no. 2, pp. 297-303, 1991.

[57] X. Ge, K. Trabbic-Carlson, A. Chilkoti, and C. D. M. Filipe, "Purification of an elastin-like fusion protein by microfiltration," Biotechnology and Bioengineering, vol. 95, no. 3, pp. 424432, 2006.

[58] M. Shimazu, A. Mulchandani, and W. Chen, "Thermally triggered purification and immobilization of elastin-OPH fusions," Biotechnology and Bioengineering, vol. 81, no. 1, pp. 74-79, 2003.

[59] L. Santi, A. Giritch, C. J. Roy, et al., "Protection conferred by recombinant Yersinia pestis antigens produced by a rapid and highly scalable plant expression system," Proceedings of the National Academy of Sciences of the United States of America, vol. 103, no. 4, pp. 861-866, 2006.

[60] A. M. Zelada, G. Calamante, M. de la Paz Santangelo, et al., "Expression of tuberculosis antigen ESAT-6 in Nicotiana tabacum using a potato virus X-based vector," Tuberculosis, vol. 86, no. 3-4, pp. 263-267, 2006.

[61] R. E. Weir, P. E. M. Fine, S. Floyd, et al., "Comparison of IFN- $\gamma$ responses to mycobacterial antigens as markers of response to BCG vaccination," Tuberculosis, vol. 88, no. 1, pp. 31-38, 2008.

[62] E. M. Agger, J. P. Cassidy, J. Brady, K. S. Korsholm, C. Vingsbo-Lundberg, and P. Andersen, "Adjuvant modulation of the cytokine balance in Mycobacterium tuberculosis subunit vaccines; immunity, pathology and protection," Immunology, vol. 124, no. 2, pp. 175-185, 2008.

[63] B. M. Buddle, D. N. Wedlock, M. Denis, and M. A. Skinner, "Identification of immune response correlates for protection against bovine tuberculosis," Veterinary Immunology and Immunopathology, vol. 108, no. 1-2, pp. 45-51, 2005.

[64] I. M. Orme, "The use of animal models to guide rational vaccine design," Microbes and Infection, vol. 7, no. 5-6, pp. 905-910, 2005.

[65] M. V. B. S. Martins, M. C. B. S. Lima, N. C. Duppre, et al., "The level of PPD-specific IFN- $\gamma$-producing CD4+ T cells in the blood predicts the in vivo response to PPD," Tuberculosis, vol. 87, no. 3, pp. 202-211, 2007.

[66] T. F. Pais, R. A. Silva, B. Smedegaard, R. Appelberg, and P. Andersen, "Analysis of $\mathrm{T}$ cells recruited during delayed-type hypersensitivity to purified protein derivative (PPD) versus challenge with tuberculosis infection," Immunology, vol. 95, no. 1, pp. 69-75, 1998.

[67] M. Harboe, A. S. Malin, H. S. Dockrell, et al., "B-cell epitopes and quantification of the ESAT-6 protein of Mycobacterium tuberculosis," Infection and Immunity, vol. 66, no. 2, pp. 717723, 1998

[68] M. M. Rigano, S. Dreitz, A.-P. Kipnis, A. A. Izzo, and A. M. Walmsley, "Oral immunogenicity of a plant-made, subunit, tuberculosis vaccine," Vaccine, vol. 24, no. 5, pp. 691-695, 2006.

[69] S. R. Ong, K. A. Trabbic-Carlson, D. L. Nettles, D. W. Lim, A. Chilkoti, and L. A. Setton, "Epitope tagging for tracking elastin-like polypeptides," Biomaterials, vol. 27, no. 9, pp. 1930-1935, 2006.
[70] M. F. Shamji, H. Betre, V. B. Kraus, et al., "Development and characterization of a fusion protein between thermally responsive elastin-like polypeptide and interleukin-1 receptor antagonist: sustained release of a local antiinflammatory therapeutic," Arthritis and Rheumatism, vol. 56, no. 11, pp. 3650-3661, 2007. 

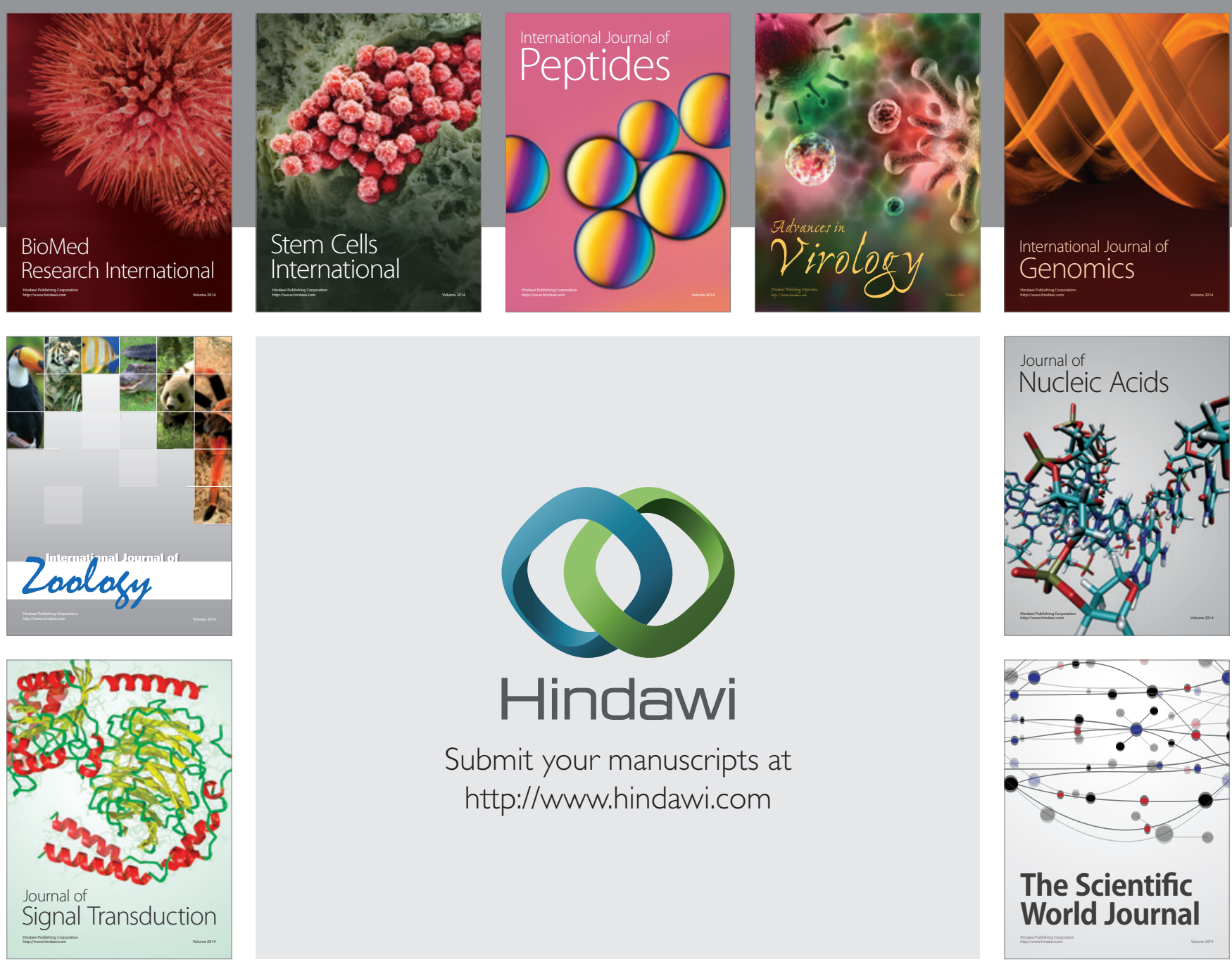

Submit your manuscripts at

http://www.hindawi.com
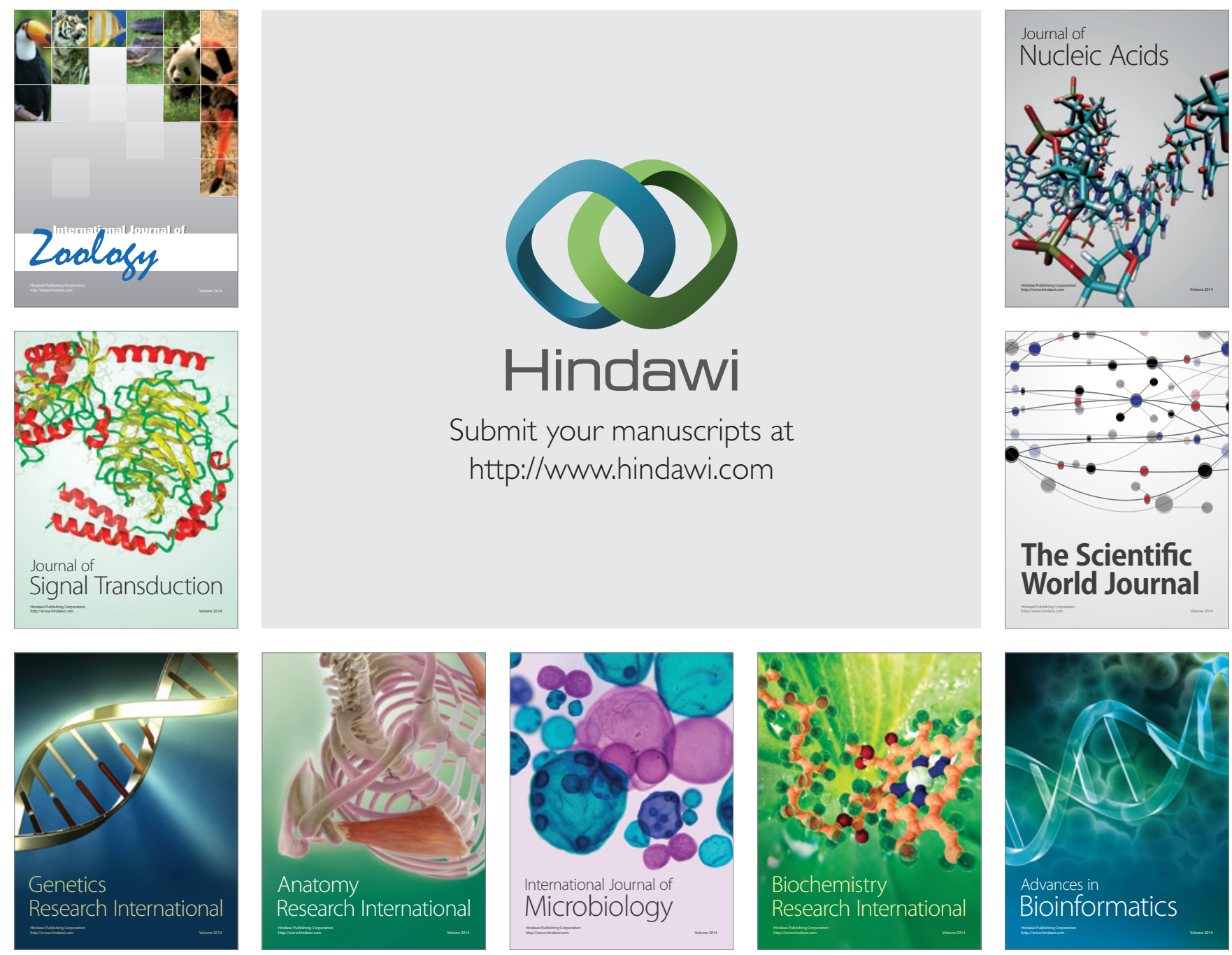

The Scientific World Journal
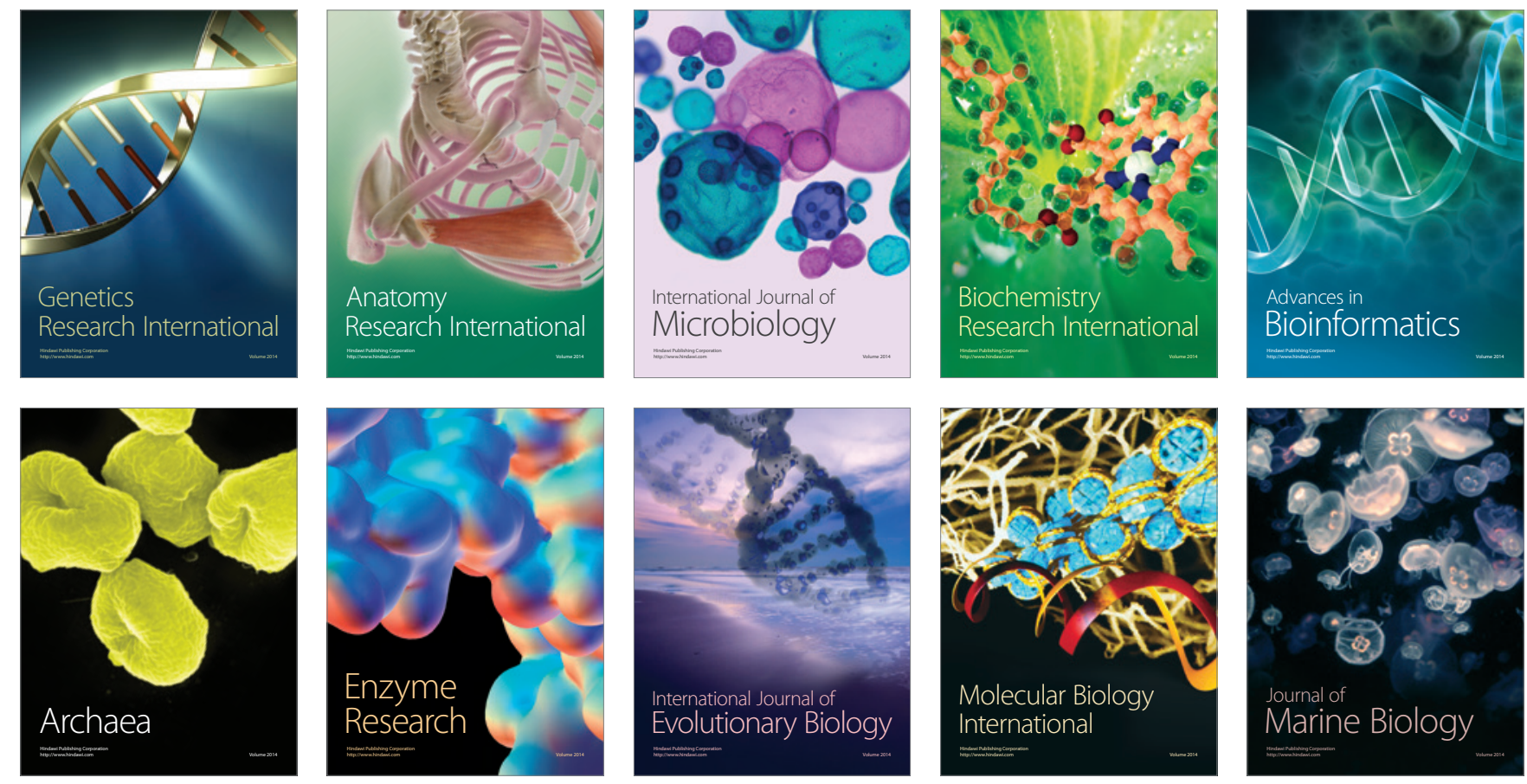